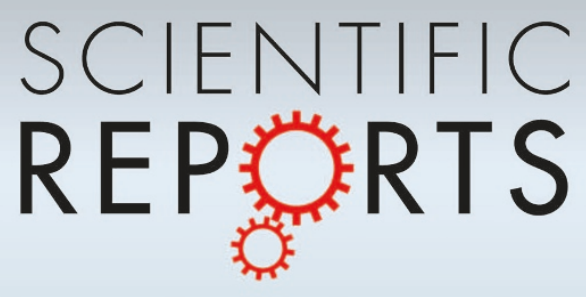

OPEN

SUBJECT AREAS:

NANOPARTICLES

MAGNETIC PROPERTIES AND

MATERIALS

OPTICAL MATERIALS

DESIGN, SYNTHESIS AND

PROCESSING

Received

15 October 2014

Accepted

23 February 2015

Published

30 March 2015

Correspondence and requests for materials should be addressed to Y.S. (songyi@ustb.edu.

cn)

* These authors contributed equally to this work.

\title{
A General Strategy for Nanohybrids Synthesis via Coupled Competitive Reactions Controlled in a Hybrid Process
}

\author{
Rongming Wang $1 *$, Wantai Yang ${ }^{2 *}$, Yuanjun Song ', Xiaomiao Shen ${ }^{3}$, Junmei Wang' ${ }^{1}$ Xiaodi Zhong ${ }^{3}$, \\ Shuai Li ${ }^{3} \&$ Yujun Song'
}

\begin{abstract}
'Department of Physics, School of Mathematics and Physics, University of Science \& Technology Beijing, Beijing 100083, China, ${ }^{2}$ College of Materials and Engineering, Beijing University of Chemical Technology, Beijing 100029, China, ${ }^{3}$ School of Materials Science and Engineering, Beihang University, Beijing 100191, China.
\end{abstract}

A new methodology based on core alloying and shell gradient-doping are developed for the synthesis of nanohybrids, realized by coupled competitive reactions, or sequenced reducing-nucleation and co-precipitation reaction of mixed metal salts in a microfluidic and batch-cooling process. The latent time of nucleation and the growth of nanohybrids can be well controlled due to the formation of controllable intermediates in the coupled competitive reactions. Thus, spatiotemporal-resolved synthesis can be realized by the hybrid process, which enables us to investigate nanohybrid formation at each stage through their solution color changes and TEM images. By adjusting the bi-channel solvents and kinetic parameters of each stage, the primary components of alloyed cores and the second components of transition metal doping $\mathrm{ZnO}$ or $\mathrm{Al}_{2} \mathrm{O}_{3}$ as surface coatings can be successively formed. The core alloying and shell gradient-doping strategy can efficiently eliminate the crystal lattice mismatch in different components. Consequently, varieties of gradient core-shell nanohybrids can be synthesized using $\mathrm{CoM}, \mathrm{FeM}, \mathrm{AuM}, \mathrm{AgM}(\mathrm{M}=\mathrm{Zn}$ or $\mathrm{Al})$ alloys as cores and transition metal gradient-doping $\mathrm{ZnO}$ or $\mathrm{Al}_{2} \mathrm{O}_{3}$ as shells, endowing these nanohybrids with unique magnetic and optical properties (e.g., high temperature ferromagnetic property and enhanced blue emission).

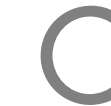
omposition and strucrue controlled hybridization has become an effective approach for realizing multifunctionality, stability and/or producing new physicochemical properties of nanomaterials due to the surface and interface enhanced properties and the synergistic effect among components ${ }^{1-24}$. With the advancement of science and technology promoted by nanohybrids, large scale, controlled-engineering of nanoparticles (NPs) becomes more and more urgent to fulfill their academic and industrial perspectives ${ }^{3,10,25-32}$. Controlled successive coating on preformed cores is one simple and effective method, but still challenging, particularly for ultra-small nanohybrids with surface coatings that are incompatible with cores (e.g., metaldielectrics or metal-semiconductors) due to their crystal lattice mismatching and large curvatures ${ }^{33}$. Besides large-scale ability, spatiotemporally thermal-dynamic control of each stage in the nanohybrids formation is required to optimize their compositions and structures. Traditional batch-wise techniques have enabled the synthesis of varieties of $\mathrm{NPs}^{10,15,33-35}$. However, They are usually limited by their low productivities and/or difficulty in spatiotemporally splitting the NP formation stages.

Microfluidic approaches have been attracting more and more attention in the NPs synthesis due to their reduced scaling up risk and the precise reaction kinetic control of each stage along the microchannel that is desired for sketching formation mechanism spatiotemporally for controlled morphology and structure ${ }^{9,17,26-30,36-40}$. Recently, a great progress has been achieved by Erdem et al. in microfluidic synthesis of NPs by developing a silicon-chip-based two-phase flow microreactor with multiple thermally-isolated zones ${ }^{41}$. This chip-based microreactor enables the separation of nucleation and growth during nanoparticle formation using $\mathrm{TiO}_{2} \mathrm{NPs}$ as model. We also invented polymer-chip-based microfluidic reactors, which can realize controlled growth of NPs by freezing the NPs solution in the microchannel with a low-temprature quenching solution $^{27,30,42,43}$. In spite of complicated fabrication process, these chip-based microreactors are capable of layerby-layer assembly, representing a milestone in the controlled scale-out synthesis of nanoparticles. We further developed simple programmed microfluidic processes (SPMPs), which have shown great powers in spatiotemporally splitting the NP formation and scale-out features ${ }^{16,43}$. Herein, we extend SPMPs to a sequenced microfluidic and batch-cooling process with stage-controlled reaction kinetics. Growth of nanoparticles can be 
well-terminated at the defined stage by rapid cooling the reaction solution from the microchannel in the collecting receiver with steeply reduced temperature. This hybrid process was then used in the structure and composition controlled synthesis of nanohybrids by coupling competitive reactions, or sequenced reducing-nucleation and co-precipitation, which were realized by introducing a second metal salt with low electrochemical potential (i.e., $\mathrm{AlCl}_{3}, \mathrm{ZnCl}_{2}$ ) into the primary-metal-salt solution.

Similar as our previous results ${ }^{16,43}$, the latent time of nucleation in the coupled competitive reactions and the growth of nanoparticles can be well-controlled due to the formation of controllable intermediates. Thus, spatiotemporal-resolved synthesis can be realized by this hybrid process, which enables us to investigate nanohybrid formation at each stage through their solution color changes and TEM images for optimizing their compositions and structures. By adjusting the bi-channel solvents and kinetic parameters (e.g., reactant concentrations, flow rates and reaction temperatures) at each stage, the primary components with alloyed cores and the second components with the primary metal gradient-doping $\mathrm{ZnO}$ or $\mathrm{Al}_{2} \mathrm{O}_{3}$ as surface coatings can be successively formed. The implied alloying and gradient-doping strategy can efficiently eliminate the crystal lattice mismatch in core and shell components. Consequently, ultra-small magnetic-dielectrics (e.g., $\mathrm{FeAl} @ \mathrm{Al}_{(1-\mathrm{x})} \mathrm{Fe}_{\mathrm{x}} \mathrm{O}_{\mathrm{y}}$ ), magneticsemiconductors (e.g., CoZn@ $\mathrm{Zn}_{(1-\mathrm{x})} \mathrm{Co}_{\mathrm{x}} \mathrm{O}_{\mathrm{y}}$ ), plasmon-dielectrics (e.g., $\mathrm{AgAl} @ \mathrm{Al}_{(1-\mathrm{x})} \mathrm{Ag}_{\mathrm{x}} \mathrm{O}_{\mathrm{y}}$ ) and plasmon-semiconductors (e.g., AuZn@ $\left.\mathrm{Zn}_{(1-\mathrm{x})} \mathrm{Au}_{\mathrm{x}} \mathrm{O}_{\mathrm{y}}\right)$ NPs of unique magnetic and optical properties can be synthesized using N-methyl-2-pyrrolidone (NMP) and/or water as bichannel solvents at a wide range of flow rates.

\section{Results}

Figure s1 in supporting information (SI) shows the typical experiment setup of the sequenced microfluidic and batch-cooling process ${ }^{16,43}$. This setup includes: one syringe pump for the metal-salt solution (e.g., $\mathrm{FeCl}_{2}$ and/or $\mathrm{CoCl}_{2}$ in NMP mixed with polyvinylpyrrolidone (PVP)) (1); one syringe pump for the reducing-agent solution (e.g., $\mathrm{NaBH}_{4}$ in NMP) (2); two preheating stainless steel spirals (3-4) immersed in the thermostatic tank 1 (inner diameter (ID) $=$ $127 \mu \mathrm{m}$, length $(\mathrm{L})=15 \mathrm{~cm})$ for the heating of the metal-salt solution and the reducing-agent solution from $20^{\circ} \mathrm{C}$ to $200^{\circ} \mathrm{C}$; one $\mathrm{Y}$ mixer (ID $=250 \mu \mathrm{m}$ or more, $\mathrm{L}=4 \sim 5 \mathrm{~mm}$ ) for the reactants to react to form precursors and then to initiate nucleation (5); one microtubing spiral (ID $=127 \sim 500 \mu \mathrm{m}, \mathrm{L}=10 \sim 60 \mathrm{~cm}$ or more) in the thermostatic tank 2 with temperature from $20^{\circ} \mathrm{C}$ to $200^{\circ} \mathrm{C}$ for finishing nucleation and growth of nanoparticles (6); and one product receiver (7) protected by inert gas (i.e., $\mathrm{N}_{2}$ ), with temperature controlled from $-15^{\circ} \mathrm{C}$ to $200^{\circ} \mathrm{C}$ by a chiller and/or an oil heating bath in the thermostatic tank 3 . The heating process of tank 1 , tank 2 and tank 3 is controlled by the oil bath with the boiling point of oil about $260^{\circ} \mathrm{C}$. Therefore, the temperature range for reaction can be extended up to $200^{\circ} \mathrm{C}$ using high boiling temperature solvents (e.g., NMP). The residence time in tank 1 and tank 2 can be conveniently conrolled by the flow rate, the length and diameter of the microchannel. The mean residence time in tank 3 depends on the flow rate and the reactant volume in the syringe. For example, the mean residence time is about $10 \mathrm{mins}$ if the flow rate is controlled at $1.0 \mathrm{~mL} / \mathrm{min}$ for each syringe pump and the reactant solution in each syringe is $20 \mathrm{~mL}$. The temperature in the tank 3 is usually controlled no more than $15^{\circ} \mathrm{C}$ to freeze the growth of nanoparticles for desired sizes and undesired Ostwald ripening.

To realize multi-functionalization and/or robust surface protection in single NPs, alloyed core-shell NPs or oligomer NPs with alloy cores and surface oxide coatings are expected to work ${ }^{9,10,19,23,30}$. However, the surface coating of materials different from cores usually is very challenging by conventional epitaxial growth, particularly for those with crystal lattices mismatching with the cores. To achieve this aim, a new synthesis strategy, or in-situ reduction of mixed- metal ions and precipitation of second-metal oxides by forming alloys as cores and doping/mixed oxides as shells or surface-coatings, was developed by directly introducing the second-metal-salts with low standard electrode potentials (i.e., $\mathrm{Zn}^{2+}$ : $\mathrm{V}_{0}=-0.763 \mathrm{~V} ; \mathrm{Al}^{3+}$ : $\mathrm{V}_{0}=-1.662 \mathrm{~V}$ ) into the primary-metal-salt solutions (i.e., $\mathrm{CoCl}_{2}$ and/or $\mathrm{FeCl}_{2}, \mathrm{HAuCl}_{4}, \mathrm{AgNO}_{3}$ ). According to their standard electrode potentials, the primary-metal salts will be reduced into atoms more easily and quickly than the second-metal salts. Simutaneously, nucleation of these atoms into nanocrystals will form a competitive process with the co-precipitation of these metal ions to form metal hydroxides and then metal oxides. The former process is usually a little bit faster than the later. As a result, the preformed tiny $\mathrm{Co}, \mathrm{Fe}$, or $\mathrm{CoFe}, \mathrm{Au}, \mathrm{Ag}$ nanocrystallites after nucleation firstly will be surrounded by the second-metal ions. Since the reduction of the second-metal ions into atoms cannot be ruled out, these atoms will be alloyed into these nanocrystallites, forming alloy cores. Along with the reduction reaction, the $\mathrm{pH}$ value of the reaction solution changes, leading to the acceleration of co-precipitation of these metal ions into hydroxide species. Surfaces of these preformed alloy nanocrystallites (i.e., $\mathrm{Zn}$ or $\mathrm{Al}$ alloyed $\mathrm{Co}, \mathrm{Fe} \mathrm{Au,} \mathrm{Ag}$ or CoFe NPs) can perform as nucleation sites for the precipitation reactions, consequently forming mixed metal hydroxide coatings on these alloy cores ${ }^{44,45}$. These metal hydroxides can be further transferred into metal oxides by dehydration in the post treatment, forming oxide shells or coatings. Some of the primary- or second-metal atoms on surfaces or near surfaces of the alloy cores can be redoxed or even directly collided into the oxide shells or coatings to form the metal atom/ion doping passivation layer ${ }^{46,47}$. In addition, some primary-metal ions and reducing agents can be included into the second-metal hydroxides during the co-precipitation, finally forming the second metal oxide coatings doped by the primary metal. The primary or the second metal ions can be reduced into atoms by the reducing agents included in the coatings and the reduced second metal atoms in the surface coatings can also reduce the primary metal ions into atoms. These metal atoms may gradually diffuse from the surface coatings into the cores, which can increase the core size slightly. With the growth of particles and the reform of the surface coatings during the collecting stage in the cooling reciever, the above effects will lead to the formation of the primary metal cores alloyed by the second metal atoms and the second metal oxide shells gradient-doped by the primary metal atoms/ions.

This strategy is demonstrated by the synthesis of magneticdielectrics (MAl@ $\mathrm{Al}_{(1-\mathrm{x})} \mathrm{M}_{\mathrm{x}} \mathrm{O}_{\mathrm{y}}$ ) and magnetic-semiconductors (MZn@ $\mathrm{Zn}_{(1-\mathrm{x})} \mathrm{M}_{\mathrm{x}} \mathrm{O}_{\mathrm{y}}$ ) nanohybrids ( $\mathrm{M}=\mathrm{Co}, \mathrm{Fe}, \mathrm{Ag}, \mathrm{Au}$, etc.) as models by introducing the competitive reducing-nucleation and precipitation reaction using all NMP-phased reaction systems, or NMP as bi-channel solvents. Similar as in the case of $\mathrm{CoFe} \mathrm{NPs}^{43}$, the formation process of these nanohybrids can also be spatiotemporally divided into 4 stages. The first stage is the formation of organometallic intermediates by the reduction reaction. The primary metal salts and some of the second metal salts in NMP are reduced into metal atoms by $\mathrm{NaBH}_{4}$ (rx-1). These metal atoms can be coordinated by the 5 -membered cyclic lactam in PVP and/or NMP to form kinetic stable organometallic intermediates ( $\mathrm{rx}-2)$ before nucleation. Simultaneously, $\mathrm{Zn}^{2+}$ and $\mathrm{Al}^{3+}$ ions can react with $\mathrm{NaBH}_{4}$ to form relatively stable zinc or aluminum borohydrides ( $\mathrm{rx}-4, \mathrm{rx}-5)$, which can decompose either to metal hydrides rapidly ( $\mathrm{rx}-6, \mathrm{rx}-7)$ or to metallic atoms (zinc or aluminum, rx- 8 and $\mathrm{rx}-9$ ) stabilized by the 5 -membered cyclic lactams, similar as $\mathrm{rx}-3^{46,47}$. The second stage is the nucleation stage by the competitive reducing-nucleation and precipitation. These kinetic stable intermediates will nucleate to form tiny nanocrystallites after the kinetic parameter is changed (e.g., elevated temperature or proton solvents $\mathrm{H}_{2} \mathrm{O}$ ) (rx-3). These zinc or aluminum atoms can mix with those primary-metal atoms if a transient nucleation occurs, leading to the formation of alloyed-metal nuclei. Depending on the solution $\mathrm{pH}$ value, the formed second metal hydrides can either reduce the primary metal ions (e.g., $\mathrm{Fe}^{2+}$ or 
$\mathrm{Co}^{2+}$ ) into atoms or re-decompose into metal ions (rx-10 and rx-11) that will form metal hydroxides (rx-12 and rx-13) surrounding or even directly precipitating on the alloyed-metal nuclei surfaces ${ }^{44,45}$. Note: the primarily formed surface coatings are not complete or very loose. The third stage is the growth stage: the alloyed metal nuclei with partial coatings or loose shells will grow up to form final nanohybrids. These metal atoms formed in the previous 2 stages can be stabilized by PVP and NMP again (rx-2), and then be absorbed by the coated nuclei, and finally be recrystallized into the alloyed cores or traped in the coatings through diffusion. Simultaneously, the formed-metal hydroxides continue depositing on the surface of the preformed alloyed nuclei to increase the coating thickness that will gradually increase the diffusion resist of atoms or ions between surface coatings and cores. Consequently, nanohybrids formed by alloy cores and the second metal oxides gradient-doped by the primary metal atoms/ions as shells can be synthesized, whose growth can be frozen or retarded in the temperature rapidly-reduced receiver during the $4^{\text {th }}$ termination stage. Clearly, these active metal atoms ( $\mathrm{Zn}$ or $\mathrm{Al})$ in the alloy cores can be used as sacrificed metal atoms to protect the oxidization of the primary-metal atoms by forming a thin layer of the second-metal oxides $\left(\mathrm{ZnO}\right.$ or $\mathrm{Al}_{2} \mathrm{O}_{3}$ ). As a result, by adding $\mathrm{ZnCl}_{2}$ or $\mathrm{AlCl}_{3}$ into the primary-metal-salt solutions above, hybrid metal-dielectrics with the primary metal doping $\mathrm{Al}_{2} \mathrm{O}_{3}$ as coatings or hybrid metal-semiconductors with the primary metal doping $\mathrm{ZnO}$ as coatings can be obtained, respectively. By this alloying and gradient-doping strategy, lattice mismatch between cores and shells can be eliminated efficiently.

$\mathrm{M}^{n+}+n \mathrm{NaBH}_{4}+\frac{3 n}{2} \mathrm{H}_{2} \mathrm{O} \rightarrow \mathrm{M}+n \mathrm{Na}^{+}+\frac{3 n}{2} \mathrm{~B}_{2} \mathrm{O}_{3}+7 n \mathrm{H}_{2} \uparrow(\mathrm{rx}-1)$
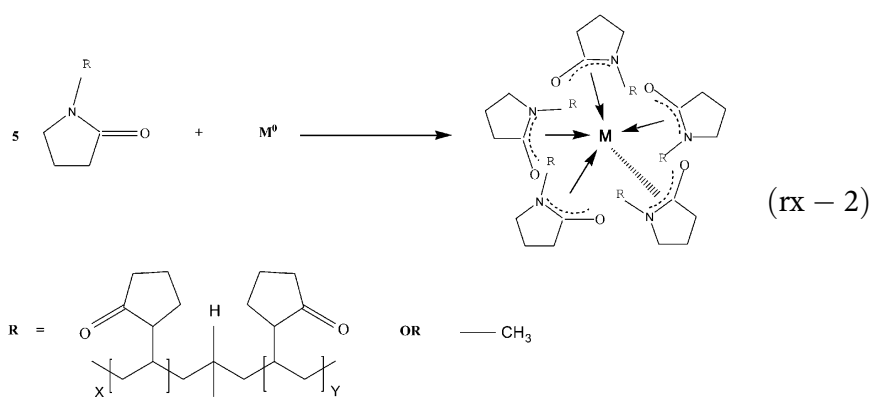

Similar as in the case of CoFe NPs, these new reaction systems to synthesize nanohybrids by competitive reduction and precipitation of mixed metal salts are often accompanied by color changes, such as the formation of grey or white organometallic intermediates ( $r x-2$, rx-3). Most important, the stability of these intermediates can be increased after adding the second metal salt into the primary metal salt solution, which makes it more convenient to identify each stage and optimize their kinetic parameters simply by color changes. Morphologies and structures of nanohybrids at different stages were characterized by TEM images, correlating with the reaction solution colors at different stages using the synthesis of magneto-dielectrics (i.e., FeAl@ $\mathrm{Al}_{(1-\mathrm{x})} \mathrm{Fe}_{\mathrm{x}} \mathrm{O}_{\mathrm{y}} \mathrm{NPs}$ ) as example. The reaction solutions of formed intermediates, nucleation, growth, termination (collecting), Ostwald ripening and aggregation were obtained by tunning the residence time in the microchannel and the collecting time in the cooling receiver, which is controlled by channel lengths at a controlled reaction temperature and flow rate (details in Part I of SI).

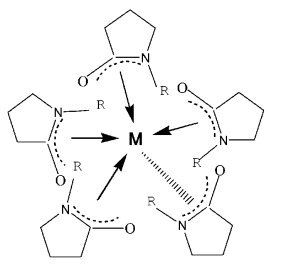

High $\mathrm{T}$ or $\mathrm{H}_{2} \mathrm{O}$ $\left[(M)_{x}(P V P-N M P)_{y}\right]_{\text {nanocrysta }}$

$(\mathrm{rx}-3)$

$$
\begin{array}{cc}
\mathrm{Zn}^{2+}+\mathrm{BH}_{4}^{-} \rightarrow \mathrm{Zn}\left(\mathrm{BH}_{4}\right)_{2} & (\mathrm{rx}-4) \\
\mathrm{Al} l^{3+}+3 \mathrm{BH}_{4} \rightarrow \mathrm{Al}\left(\mathrm{BH}_{4}\right)_{3} & (\mathrm{rx}-5) \\
\mathrm{Zn}\left(\mathrm{BH}_{4}\right)_{2} \rightarrow \mathrm{ZnH}_{2}+2 \mathrm{BH}_{3} & (\mathrm{rx}-6) \\
\mathrm{Al}\left(\mathrm{BH}_{4}\right)_{3} \rightarrow \mathrm{AlH}_{3}+3 \mathrm{BH}_{3} & (\mathrm{rx}-7) \\
\mathrm{Zn}\left(\mathrm{BH}_{4}\right)_{2} \rightarrow \mathrm{Zn}^{0}+\mathrm{B}_{2} \mathrm{H}_{6}+\mathrm{H}_{2} \uparrow & (\mathrm{rx}-8) \\
\mathrm{Al}(\mathrm{BH})_{3} \rightarrow \mathrm{Al}^{0}+3 / 2 \mathrm{~B}_{2} \mathrm{H}_{6}+3 / 2 \mathrm{H}_{2} \uparrow & (\mathrm{rx}-9) \\
\mathrm{ZnH}_{2}+2 \mathrm{H}^{+} \rightarrow \mathrm{Zn}^{2+}+2 \mathrm{H}_{2} \uparrow & (\mathrm{rx}-10) \\
\mathrm{AlH} \mathrm{H}_{3}+3 \mathrm{H}^{+} \rightarrow \mathrm{Al}^{3+}+3 \mathrm{H}_{2} \uparrow & (\mathrm{rx}-11) \\
n \mathrm{ZnH} \mathrm{H}_{2}+2 \mathrm{M}^{n+}+2 n\left(\mathrm{OH}^{-}\right) \rightarrow 2 \mathrm{M}^{0}+n \mathrm{Zn}(\mathrm{OH})_{2}+n \mathrm{H}_{2} \uparrow & (\mathrm{rx}-12) \\
n A l H_{3}+3 M^{n+}+3 n\left(\mathrm{OH}^{-}\right) \rightarrow 3 M^{0}+n \mathrm{Al}(\mathrm{OH})_{3}+3 n / 2 \mathrm{H}_{2} \uparrow(\mathrm{rx}-13)
\end{array}
$$

The mixed metal salt solution $\left(\mathrm{FeCl}_{2}\right.$ and $\left.\mathrm{AlCl}_{3}\right)$ changes from yellow to white (Fig. 1a-i) as the reaction proceeds about 0.29 second $\left(\mathrm{L}_{\text {total }}=10 \mathrm{~cm}\right)$ after it mixes with the reducing solution in the micro-mixer, indicating the formation of intermediates. As the intermediates were observed by TEM, most areas only show solute contaminating (local foggy areas) amorphous carbon film (Fig. 1a-ii). A few of nanocrystallinities (Fig. s2a) about $1.8 \pm 0.4 \mathrm{~nm}$ (Fig. s2b) can be rarely found, which can be attributed to the localized initial nucleation due to the rapidly-increased local concentration by the solvent evaporation during the TEM sample preparation. The white intermediate solution will change to light-brown (Fig. 1b-i) and lots of highly-crystallized nanocrystals (Fig. 1b-ii) about $3.7 \pm 0.6 \mathrm{~nm}$ (Fig. s2c) can be observed if the reaction proceeds for additional 0.15 second $\left(\mathrm{L}_{\text {total }}=15 \mathrm{~cm}\right)$, indicating that the nucleation occurs. Since the nucleation is very fast, a slight growth of NPs in the microchannel and during the TEM sample preparation cannot be avoided. Thus, these nanoparticles are almost twice bigger than those observed in Figure 1a-ii and surface coatings can be clearly observed in many of them (inset in Fig. 1b-ii). The reaction solution becomes brown (Fig. $1 \mathrm{c}-\mathrm{i})$ as the reaction proceeds for additional 0.59 second $\left(\mathrm{L}_{\text {total }}\right.$ $=35 \mathrm{~cm}$ ). Interestingly, many of larger particles and lots of smaller particles can be observed (Fig. 1c-ii) in this stage. This is a common phenomena often observed during nanoparticle formation, where many larger particles will be formed by absorbing the solutes released from the smaller particles, or Ostwald ripening (OR), leading to a reduced mean diameter $(3.1 \pm 0.6 \mathrm{~nm}$, Fig. s2d). The surface coatings of many NPs become thinner (inset in Fig. 1c-ii) than those NPs in Fig. 1b-ii. Clearly, these NPs preserve good crystalline cores but a little bit disordered surfaces, indicating that it is the surface coatings that firstly dissolve into the solution during OR, which can protect the cores from dissolving too fast. As the reaction proceeds for additional 1.33 seconds $\left(\mathrm{L}_{\text {total }}=60 \mathrm{~cm}\right)$, the solution color becomes black (Fig. 1d-i). Surprisely, morphologies and crystal structures in NPs change dramatically (Fig. 1d-ii). Core shell morphology becomes more distinct, with cores of $3.1 \pm 0.7 \mathrm{~nm}$ and the total diameter of $6.9 \pm 2.5 \mathrm{~nm}$ (Fig. s2e, s2f). This result indicates that the elongated OR is mainly to increase the shell thickness $(1.9 \mathrm{~nm})$ since the core size changes little as comparing with that of the previous stage. Clearly, both shells and cores become amorphous (inset in Fig. 1dii) by comparing with those highly-crystallized NPs in the previous stages (Fig. 1b-ii and 1c-ii), indicating the reform of crystal structures both in cores and shells possibly due to the inclusion of metalloid 

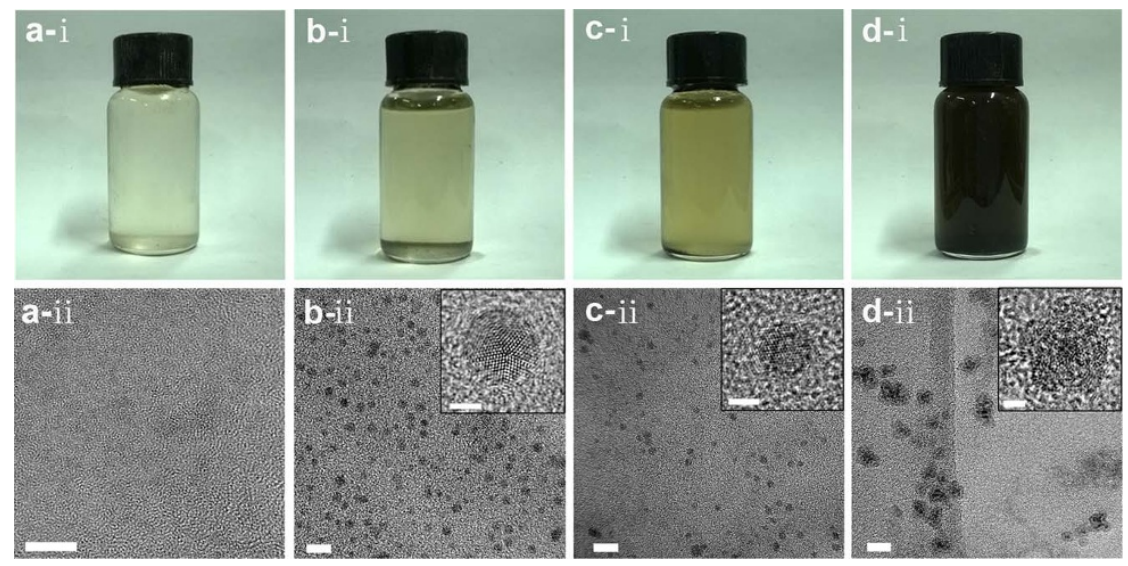

Figure 1 Reaction solution color change and TEM image of the resulted particle at different resident time in microfluidic channels after the reductant solution is mixed with the mixed metal salt solution using $\mathrm{FeAl} @ \mathrm{Al}_{(1-\mathrm{x})} \mathrm{Fe}_{\mathrm{x}} \mathrm{O}_{\mathrm{y}}$ (the $\mathrm{FeCl}_{2}$ and $\mathrm{AlCl}_{3}$ in $\mathrm{NMP}$ shows yellow color) as example. Color changes of the reaction solutions ( $a-i, b-i, c-i$ and d-i) and TEM images of the formed nanoparticle (a-ii, b-ii, c-ii, d-ii) after the reaction proceeds about $0.39 \mathrm{~s}\left(\mathrm{~L}_{\text {total }}=10 \mathrm{~cm}\right), 0.44 \mathrm{~s}\left(\mathrm{~L}_{\text {total }}=15 \mathrm{~cm}\right), 1.03 \mathrm{~s}\left(\mathrm{~L}_{\text {total }}=35 \mathrm{~cm}\right)$ and $1.77 \mathrm{~s}\left(\mathrm{~L}_{\text {total }}=60 \mathrm{~cm}\right)$, respectively. $\mathrm{L}_{\text {total }}$ : the total microchannel length after the Y-mixer (5) in Fig. s1.

boron and the doped second metal oxides (e.g., $\mathrm{Al}_{2} \mathrm{FeO}_{4}$ ) during $\mathrm{OR}$. Therefore, termination of the growth at desired stage and the elimination of Ostwald ripening are very crucial in the morphology (size and surface coatings) and crystal structure control of nanohybrids. Otherwise, these NPs will experience Ostwald ripening where the random growth and reforming of surface coatings, interfaces and/ or cores may occur, leading to broad size dispersion and/or structure change in each component.

After the systematical investigation of the reaction kinetics, nanohybrids with uniform morphology and good crystallinity can be obtained as the growth time in the microchannel is controlled in $0.30-0.45$ second $\left(\mathrm{L}_{\text {total }}=25-30 \mathrm{~cm}\right)$ and then the solution is collected in the cooling receiver (the resident time: $\sim 20 \mathrm{~min}$ ), where the light-brown solution becomes brown (Fig. 2a: right-bottom inset). The detailed reaction conditions are described in Part I of SI, together with those for other typical nanohybrids. As shown in Fig. 2a, uniform NPs with a mean diameter of $4.8 \pm 0.3 \mathrm{~nm}$ (Fig. s3a-i) can be obtained. Even though the core shell structure is not so distinct, contrast differences between the inner parts and the surface layers can be observed from one typical HRTEM image (Fig. 2a: right-top inset; Fig. s4a) in spite of eccentric in shape. The STEM-HAADF (Zcontrast) images equipped with Gatan GIF 2000 energy filter system and energy dispersive X-ray spectrometries (EDX) for some typical particles were performed. Figure $2 b$ is the STEM-HAADF image for one typical single particle, showing clear contrast difference between the center and the surface layer. The atom ratios between $\mathrm{Fe}$ and $\mathrm{Al}$ recorded by point-by-point EDX scanning (point step: $\sim 1.6 \mathrm{~nm}$ ) show a significant change from the surface layer to the center part of this particle (Fig. 2c). The Al/Fe ratio gradually increases from 10/ 90 at the center of the core $(\sim 2.5 \mathrm{~nm}$ in diameter $)$ to $35 / 65$ at the interface between the core and the surface coating $(\sim 1.0 \mathrm{~nm}$ thick), and to $50 / 50 \sim 70 / 30$ at the out layer of the surface coating, forming an interface with gradually-decreasing Fe content.

The electronic structure of the consisting elements in the NPs can be well-defined by X-ray photoelectronic spectroscopy (XPS), giving further composition information of these NPs. The depth of the photoemitted electrons escaping from the very top surface of samples by the $\mathrm{Al} \mathrm{K} \mathrm{K}_{\alpha} \mathrm{X}$-ray source (1486.6 $\mathrm{eV}$ photons) is usually in the $0.5-$ $3 \mathrm{~nm}$ range, comparable to half of the diameters of these NPs $(\sim 4.8 \mathrm{~nm})$. Thereby, XPS can help us to obtain the electronic structures of elements in cores and coatings, or whether they are metallic or oxidized. The full XPS spectra for these samples are plotted in Fig. s5a. The full XPS spectra not only confirm the existence of Fe, $\mathrm{Al}$ and $\mathrm{O}$, but also of $\mathrm{C}, \mathrm{B}$ and $\mathrm{N}$ in the NPs. Carbon can be mainly from the stabilizer, or PVP. Boron can be possibly from the decomposition of some $\mathrm{NaBH}_{4}$ and the reducing reaction of rx-1, producing metallic boron that may be used as alloy element in metallic cores or $\mathrm{B}_{2} \mathrm{O}_{3}$ that may exist in the oxide coatings ${ }^{17}$. The nitrogen can be attributed from the stabilizer (i.e., PVP) and/or the formation of metal-nitrogen bonds as the intermediates decompose ( $\mathrm{rx}-2$ and $\mathrm{rx}-3)$.

The high resolution XPS spectrum for $\mathrm{Al}$ element (Fig. 2d) in $\mathrm{FeAl} @ \mathrm{Al}_{(1-\mathrm{x})} \mathrm{Fe}_{\mathrm{x}} \mathrm{O}_{\mathrm{y}}$ NPs shows two broad peaks centered at $73.2 \mathrm{eV}$ and $75.2 \mathrm{eV}$, which can be indexed as the signals from $\mathrm{Al}$ $2 \mathrm{p}$ binding energy (BE) of metallic $\mathrm{Al}$ and $\mathrm{Al} 2 \mathrm{p}$ bonding energy of $\mathrm{Al}$ oxides. More precisely, shoulders at $72.7 \mathrm{eV}$ and $73.4 \mathrm{eV}$ can be indexed as $2 \mathrm{p} 3 / 2$ and $2 \mathrm{p} 1 / 2$ of metallic $\mathrm{Al}$, respectively. The full XPS spectrum of $\mathrm{FeAl} @ \mathrm{Al}_{(1-\mathrm{x})} \mathrm{Fe}_{\mathrm{x}} \mathrm{O}_{\mathrm{y}} \mathrm{NPs}$ also gives $\mathrm{Al}$ 1s binding energy of metallic $\mathrm{Al}$, which can be attributed to the metallic cores. Several shoulders at $75.2-75.7 \mathrm{eV}, 74.8 \mathrm{eV}$ and $74.4 \mathrm{eV}$ can be indexed as $\mathrm{Al} 2 \mathrm{p}$ bonding energies from $\mathrm{AlO}_{\mathrm{x}}, \mathrm{Al}(\mathrm{OH})_{3}$ and $\mathrm{Al}_{2} \mathrm{O}_{3}$, respectively, which are doped by $\mathrm{Fe}$ in shells. Interestingly, there is a distinct shoulder at $73.9 \mathrm{eV}$ that can be possibly indexed as $\mathrm{Al} 2 \mathrm{p} \mathrm{BE}$ of Al-N bonds formed by the decomposition of Al-based intermediates (rx-3). The high energy resolution XPS spectrum for Fe element (Fig. 2e) in FeAl@ $\mathrm{Al}_{(1-\mathrm{x})} \mathrm{Fe}_{\mathrm{x}} \mathrm{O}_{\mathrm{y}} \mathrm{NPs}$ shows pronounced peaks at $710.3 \mathrm{eV}$ and $723.3 \mathrm{eV}$, indexed as $\mathrm{Fe} 2 \mathrm{p} 3 / 2$ and $\mathrm{Fe} 2 \mathrm{p} 1 / 2$, which suggests that iron oxides are mainly of $\mathrm{Fe}_{3} \mathrm{O}_{4}$ that is mixed with $\mathrm{Al}_{2} \mathrm{O}_{3}$ in shells by checking the peak position of $\mathrm{O} 1 \mathrm{~s}(530.7 \mathrm{eV}) . \mathrm{A}$ shoulder at $706.8 \mathrm{eV}$ can be clearly observed from the asymmetry feature of the peak at $710.3 \mathrm{eV}$, which can be attributed to the $\mathrm{BE}$ of metallic $\mathrm{Fe} 2 \mathrm{p} 3$. Combination of the $\mathrm{Fe} 3 \mathrm{~s} \mathrm{BE}$ at $92.0 \mathrm{eV}$ from the full XPS spectrum (Fig. s5a) of $\mathrm{FeAl} @ \mathrm{Al}_{(1-\mathrm{x})} \mathrm{Fe}_{\mathrm{x}} \mathrm{O}_{\mathrm{y}}$, the penetration depth of XPS (0.5-3.0 nm) and the size of FeAl@ $\mathrm{Al}_{(1-\mathrm{x})} \mathrm{Fe}_{\mathrm{x}} \mathrm{O}_{\mathrm{y}}(4.8 \mathrm{~nm})$, the existence of metallic iron in the FeAl cores of FeAl@Al $\mathrm{Al}_{(1-\mathrm{x})} \mathrm{Fe}_{\mathrm{x}} \mathrm{O}_{\mathrm{y}}$ can be reasonably confirmed by recalling the STEM-HAADF characterization. Additionally, existence of $\mathrm{FeO}$ and trace of $\alpha-\mathrm{Fe}_{2} \mathrm{O}_{3}$ are possible acccording to the shoulder at $709.4 \mathrm{eV}$ and the weak satellite peak at $718.3 \mathrm{eV}$.

The XRD pattern of these NPs (Fig. 2f) gives two broad peaks at $43.0^{\circ}$ and $62.7^{\circ}$ that represent the (110) plane and the (200) plane of bcc Fe, respectively, which is alloyed by $\mathrm{Al}$ and/or $\mathrm{B}$ according to the XPS analysis. Other three broad peaks/shoulders at $33.2^{\circ} 36.0^{\circ}$ and $60.3^{\circ}$ represent the (104) plane, the (110) plane and the (018) plane of $\alpha-\mathrm{Al}_{2} \mathrm{O}_{3}$, respectively. The $\mathrm{Al}_{2} \mathrm{O}_{3}$ layer should be doped by $\mathrm{Fe}$ and/or $\mathrm{B}$ according to the proposed formation mechanism, the above XPS and EDX characterization for the whole particles (Fig. s3a-ii).

According to the comprehensive analysis by HRTEM, STEMHAADF, XPS, XRD and EDX, it can be reasonably concluded that 
a

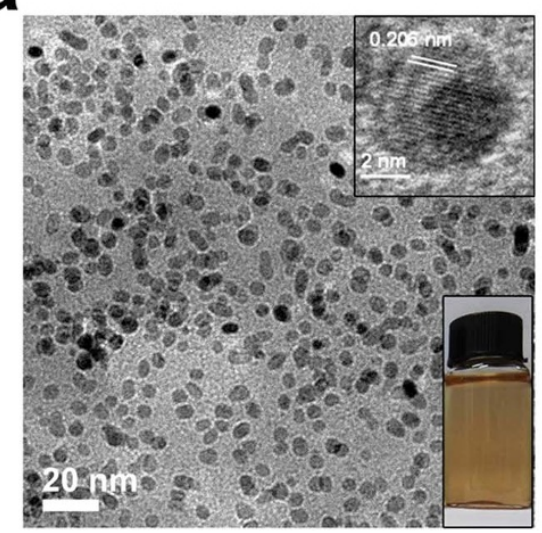

d

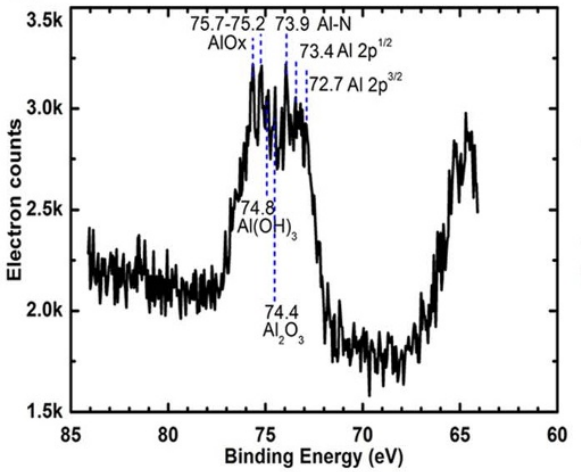

b

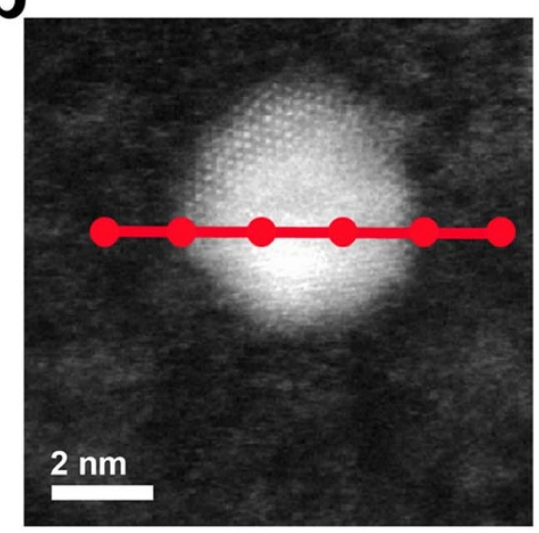

e

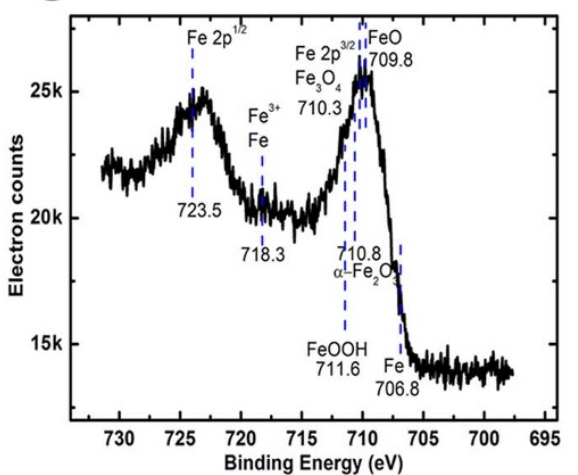

C

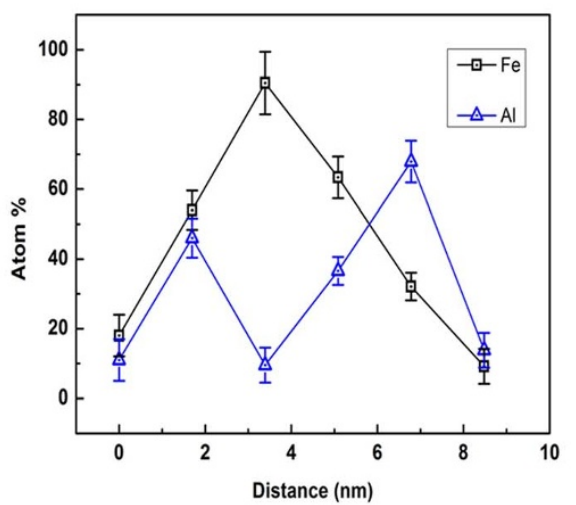

$\mathbf{f}$

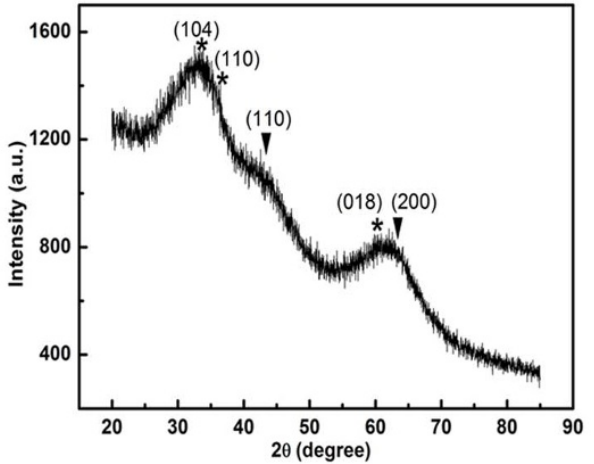

Figure $2 \mid$ Wide-viewed TEM image (a), HR-TEM image of one single particle (a: inset), STEM-HAADF image of one single particle (b), point-bypoint EDX scanning of one single particle (c), high energy resolution XPS for Al (d), high energy resolution XPS for Fe (e) and XRD (f) of FeAl@ $\mathrm{Al}_{(1-\mathrm{x})} \mathrm{Fe}_{\mathrm{x}} \mathrm{O}_{\mathrm{y}}$ nanohybrids synthesized using all NMP-phased reaction systems at a resident time of $0.73 \sim 0.88 \mathrm{~s}$ in microfluidic channel and 20 min in the cooling receiver. Right-bottom inset in Fig. 2a is the NPs solution. JCPDS No for XRD analysis: bcc Fe, 6-0696; $\alpha-\mathrm{Al}_{2} \mathrm{O}_{3}, 46-1212 ; \gamma-\mathrm{Al}_{2} \mathrm{O}_{3}, 10-0425$. In XRD (f), $\mathbf{\nabla}$ : the corresponding metallic phases; *: the corresponding metal oxides.

cores in these NPs are made of iron-rich bcc FeAl alloys and surface coatings are mainly formed by $\mathrm{Fe}$ doped $\alpha-\mathrm{Al}_{2} \mathrm{O}_{3}$ (e.g., $\mathrm{Al}_{2} \mathrm{FeO}_{4}$ or $\mathrm{AlFeO}_{3}$ ), some $\mathrm{Fe}$ doped $\mathrm{Al}(\mathrm{OH})_{3}$ coatings and trace of other kinds of $\mathrm{FeO}_{\mathrm{x}}$ and $\mathrm{AlO}_{\mathrm{x}}$. Interestingly, the $\mathrm{Al} / \mathrm{Fe}$ ratio gradually increases from the inner part to the out surface, or forming a gradient doping metal-oxide shell. This kind of hybrid structures with gradient shells gives us a main reason that these NPs do not show a large crystal lattice mismatch and a distinct core-shell contrast. Using this method, other magneto-dielectric nanohybrids, such as CoFeAl@Al $\mathrm{Al}_{(1-\mathrm{x})}(\mathrm{CoFe})_{\mathrm{x}} \mathrm{O}_{\mathrm{y}}$ and $\mathrm{CoAl} @ \mathrm{Al}_{(1-\mathrm{x})} \mathrm{Co}_{\mathrm{x}} \mathrm{O}_{\mathrm{y}}$ can be synthesized, having the similar alloyed cores and gradient-doping metal-oxide shells.

Encouraged by this success, we further extend this method in other kind of nanohybrids to test its generality, such as magnetosemiconductor nanohybrids (i.e., CoZn@ $\left.\mathrm{Zn}_{(1-\mathrm{x})} \mathrm{Co}_{\mathrm{x}} \mathrm{O}_{\mathrm{y}}\right)$. Figure 3a gives one wide-viewed TEM image of the as-synthesized CoZn@ $\mathrm{Zn}_{(1-\mathrm{x})} \mathrm{Co}_{\mathrm{x}} \mathrm{O}_{\mathrm{y}}$ nanohybrids, showing uniform dispersed size distribution. Their size statistics give a mean diameter of $3.5 \pm 0.2 \mathrm{~nm}$ (Fig. s3b-i). HRTEM image (Fig. 3a: inset) for one typical single nanoparticle shows the distinct contrast and crystal lattice differences between the surface layer and the inner part (Fig. s3b). The STEM-HAADF image (Fig. 3b) for one single CoZn@ $\mathrm{Zn}_{(1-\mathrm{x})} \mathrm{Co}_{\mathrm{x}} \mathrm{O}_{\mathrm{y}}$ particle suggests the discernable brightness contrast between the center and the surface in spite of not so sharp. The $\mathrm{Co} / \mathrm{Zn}$ atom ratios recorded by point-by-point EDX scanning show a significant change from the out surface to the center of this particle (Fig. 3c), indicating a Co core slightly alloyed by $\mathrm{Zn}$ and a $\mathrm{ZnO}$ shell heavily doped by Co by considering the formation mechanism and EDX for the whole particles (Fig. s3b-ii). Interestingly, the $\mathrm{Zn} / \mathrm{Co}$ ratio is gradually increased from the core edge $(2.5 \sim 3.0 \mathrm{~nm}$ in diameter $)$ to the out surface of the shell (1.5-2 $\mathrm{nm}$ thick), finally reaching a $\mathrm{Zn} / \mathrm{Co}$ atomic ratio of about $1: 1$.

The full XPS spectrum for CoZn@ $\mathrm{Zn}_{(1-\mathrm{x})} \mathrm{Co}_{\mathrm{x}} \mathrm{O}_{\mathrm{y}} \mathrm{NPs}$ is plotted in Figure s5b, confirming the existence of Co, Zn, O, C, B and N in these NPs, which can be attributed to the similar sources as in FeAl@ $\mathrm{Al}_{(1-\mathrm{x})} \mathrm{Fe}_{\mathrm{x}} \mathrm{O}_{\mathrm{y}} \mathrm{NPs}$. The peak at $1023.3 \mathrm{eV}$ (blueshift from the peak at $1021.7 \mathrm{eV}$ for $\mathrm{Zn} 2 \mathrm{p} 3 / 2$ ) in the high resolution XPS of $\mathrm{Zn}$ (Fig. 3d) and the peak at $782.0 \mathrm{eV}$ (blue shift from 780.5 for Co $2 \mathrm{p} 3 / 2$ ) in the high resolution XPS of Co (Fig. $3 \mathrm{e}$ ) indicate the existence of Co doping $\mathrm{ZnO}$. Both $\mathrm{ZnCoO}_{2}$ and $\mathrm{ZnCo}_{2} \mathrm{O}_{4}$ can exist in $\mathrm{CoZn} @$ $\mathrm{Zn}_{(1-\mathrm{x})} \mathrm{Co}_{\mathrm{x}} \mathrm{O}_{\mathrm{y}}$ NPs according to the STEM-HAADF-EDX analysis and the distinct shake up peaks in the high resolution XPS of Co. The asymmetry feature (low energy tails in each peak) in Figure 3d and the possible sub-peak at $778.3 \mathrm{eV}$ in Figure 3e suggest existence of metallic $\mathrm{Zn}$ and Co, which can be mainly attributed from CoZn alloy cores. According to the penetration depth of XPS on these compounds and results from the HRTEM and STEM-HAADFEDX analysis, CoZn@ $\mathrm{Zn}_{(1-\mathrm{x})} \mathrm{Co}_{\mathrm{x}} \mathrm{O}_{\mathrm{y}} \mathrm{NPs}$ should be formed by the metallic $\mathrm{Zn}$ alloyed $\mathrm{Co}$ cores and $\mathrm{Co} / \mathrm{Co}^{2+} / \mathrm{Co}^{3+}$ gradient-doping $\mathrm{ZnO}$ surface coatings. In the out surface of the coatings, there possibly exist some $\mathrm{CoOOH}, \mathrm{Co}(\mathrm{OH})_{2}$ and $\mathrm{Zn}(\mathrm{OH})_{2}$ by considering the above analysis and the proposed mechanism (existence of $\mathrm{H}_{2} \mathrm{O}$ in the base reaction environments). The possible sub-peaks from $779.2 \mathrm{eV}$ to $780.9 \mathrm{eV}$ suggest existence of varieties of cobalt oxides and cobalt hydroxides that can form $\mathrm{Co} / \mathrm{Co}^{2+} / \mathrm{Co}^{3+}$ doped $\mathrm{ZnO}$ and $\mathrm{Zn}(\mathrm{OH})_{2}$.

The XRD pattern of these NPs (Fig. 3f) gives two broad or weak peaks at $44.5^{\circ}$ and $70.0^{\circ}$ that can be indexed from the (111) plane and 


\section{a}
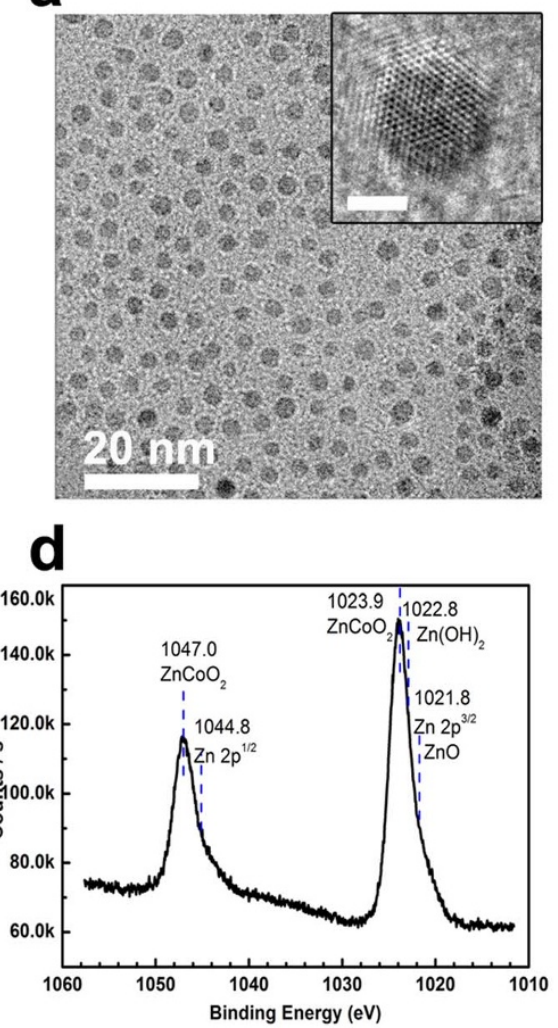

b
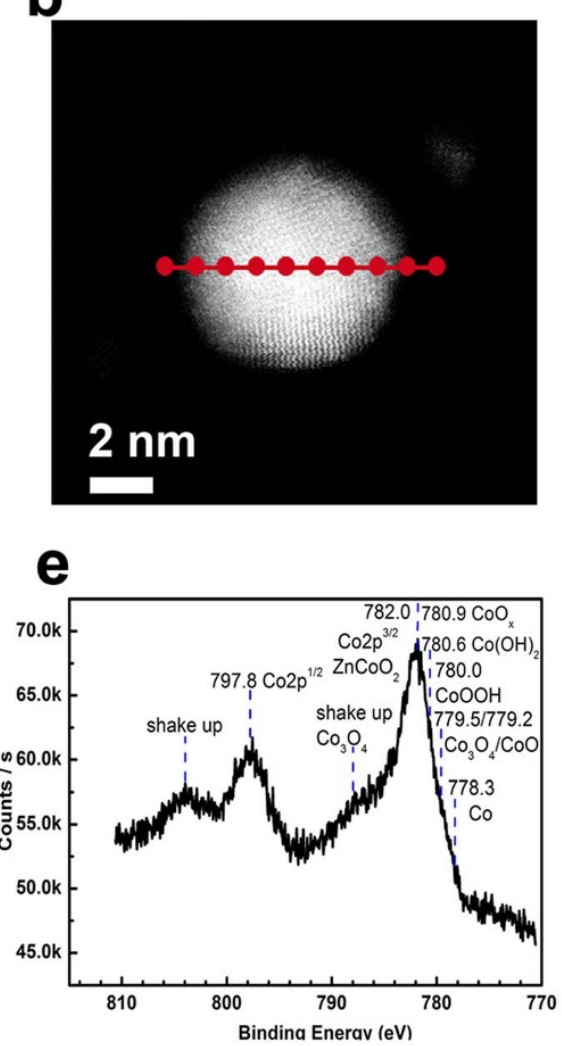
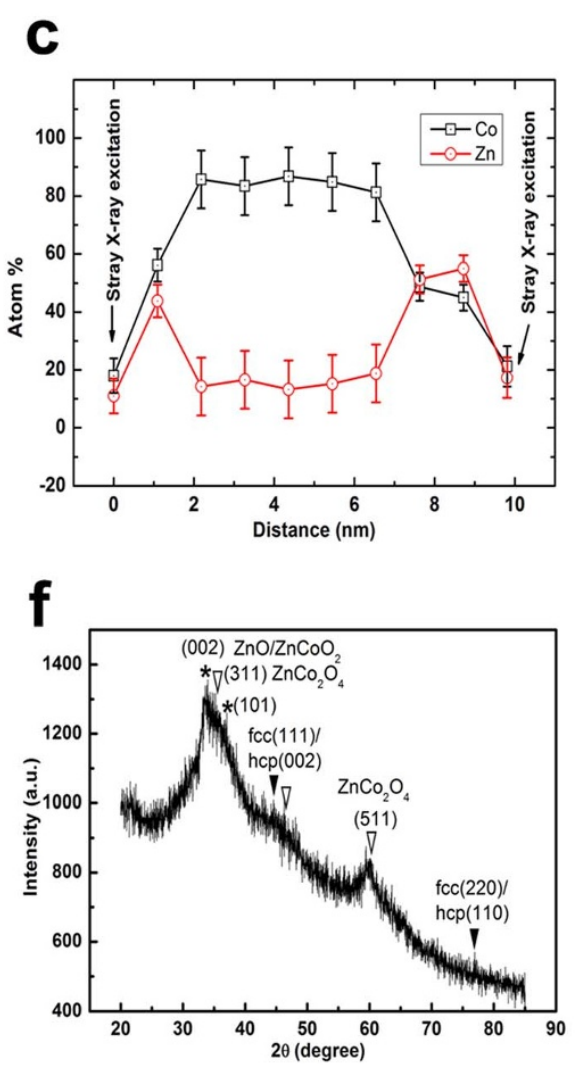

Figure 3 Wide-viewed TEM image (a), HR-TEM image of one single particle(a: inset, scale bar: $2 \mathrm{~nm}$ ), STEM-HAADF image of one single particle (b), point-by-point EDX scanning of one single particle (c), high energy resolution XPS for Zn (d), high energy resolution XPS for Co (e) and XRD (f) of CoZn@Zn $n_{(1-x)} \mathrm{Co}_{\mathrm{x}} \mathrm{O}_{\mathrm{y}}$ nanohybrids synthesized using all NMP-phased reaction systems. JCPDS No for XRD analysis: fcc Co, 15-0806; hcp Co, 05-0727; wurtzite $\mathrm{ZnO}, 36-1451$; spinel $\mathrm{ZnCo}_{2} \mathrm{O}_{4}$, 23-1390. In XRD (vi), $\mathbf{\nabla}$ : the corresponding metallic phases; $\nabla$ and *: the corresponding metal oxides.

the (220) plane of fcc Co or the (002) plane and the (110) plane of hcp Co, respectively, which is alloyed by $\mathrm{Zn}$ and/or B according to the XPS analysis and peak shifts. Other two broad peaks and shoulders at $33.8^{\circ}, 35.3^{\circ}, 36.9^{\circ}, 46.4^{\circ}, 59.9^{\circ}$ represent the $(002)$ plane of wurtzite $\mathrm{ZnO}$ (PDF 36-1451) possibly doped by $\mathrm{Co}^{2+} / \mathrm{Co}\left(\mathrm{ZnCoO}_{2} / \mathrm{ZnCoO}\right)$, the (311) plane of cubic $\mathrm{ZnCo}_{2} \mathrm{O}_{4}$, the (101) plane of wurtzite $\mathrm{ZnO}$ possibly doped by $\mathrm{Co}^{2+} / \mathrm{Co}$, the (400) plane and the (511) plane of cubic $\mathrm{ZnCo}_{2} \mathrm{O}_{4}$, respectively, which may be mixed by $\mathrm{B}_{2} \mathrm{O}_{3}$ according to the peak shifts, the proposed formation mechanism and the XPS and EDX characterization of the whole particles (Fig. s3b-ii). Recalling the STEM and XPS analysis, the XRD results suggest the existence of $\mathrm{ZnCo}_{2} \mathrm{O}_{4}$ at out surface layer and $\mathrm{ZnCoO} / \mathrm{ZnCoO}_{2}$ at sub-surface layer of the metal oxide shell.

According to the above analysis by HRTEM, STEM-HAADFEDX, XPS, XRD and EDX, it can be reasonably concluded that cores in these NPs are made of cobalt-rich fcc/hcp CoZn alloys and surface coatings are mainly formed by $\mathrm{Co} / \mathrm{Co}^{2+}$ doped $\mathrm{ZnO}$ (e.g., $\mathrm{ZnCoO}$ or $\mathrm{ZnCoO} 2$ ) and $\mathrm{ZnCo}_{2} \mathrm{O}_{4}$, some $\mathrm{Co} / \mathrm{Co}^{2+} / \mathrm{Co}^{3+}$ doped $\mathrm{Zn}(\mathrm{OH})_{2}$, some $\mathrm{CoOOH}$ and $\mathrm{Co}(\mathrm{OH})_{2}$, and/or some $\mathrm{B}_{2} \mathrm{O}_{3}$ inclusion. Similar as $\mathrm{FeAl} @ \mathrm{Al}_{(1-\mathrm{x})} \mathrm{Fe}_{\mathrm{x}} \mathrm{O}_{\mathrm{y}}$, a $\mathrm{Co} / \mathrm{Co}^{2+} / \mathrm{Co}^{3+}$ gradient-doping $\mathrm{ZnO}$ shell is formed.

As using all NMP-phased reaction systems, it was found that the latent time for the intermediates to nucleate became so long that the reaction had to be controlled at very low flow rates (usually $\leq 1.0 \mathrm{~mL}$ / min) if the reaction temperature was controlled below $90^{\circ} \mathrm{C}$ and the primary-metal-salt concentrations were controlled below $50 \mathrm{mmol} / \mathrm{L}$. Otherwise, long tube is required so that more energy and construction materials are needed. The enhanced stability of intermediates, possibly due to the ion effects from the addition of the second-metalsalt (i.e., $\mathrm{ZnCl}_{2}$ or $\mathrm{AlCl}_{3}$ ), is not desired for high productivity even though it provides additional control time for nucleation. Starting investigation of the difference in reactivity between dry and hydrated metal salts and sequential bottle-batch experiments, we found that water could significantly enhance the formation of NPs by a mechanism of accelerating intermediate decomposition (rx-3) for rapid nucleation. This eventually directs toward developing another reaction system based on NMP-phased reductants (A, Fig. s1) and aqueous-phased metal salts (B, Fig. s1). Rapid reaction after mixing $A$ and B enables to increase flow rates (e.g., from $0.8 \sim 1.0 \mathrm{~mL} / \mathrm{min}$ to $3.0 \sim$ $5.0 \mathrm{~mL} / \mathrm{min}$ or higher) for narrow nucleation stage, which is of great benefit for high productivity.

By this new reaction system, one magneto-semiconductor nanohybrid (i.e., CoZn@ $\mathrm{Zn}_{(1-\mathrm{x})} \mathrm{Co}_{\mathrm{x}} \mathrm{O}_{\mathrm{y}}$ ) was firstly synthesized at a high flow rate of $3.0 \mathrm{~mL} / \mathrm{min}$ as model (detailed synthesis condition in Part I of SI and Table 1). Figure 4a is the TEM image of CoZn@ $\mathrm{Zn}_{(1-\mathrm{x})} \mathrm{Co}_{\mathrm{x}} \mathrm{O}_{\mathrm{y}}$ NPs synthesized by the aqueous-phased metal salt process, suggesting a narrow size distribution. Statistics on their diameters give a mean diameter of $4.4 \pm 0.4 \mathrm{~nm}$ (Fig. s3c-i). The core shell contrast between the inner part and the surface layer can be clearly observed from the HRTEM image for one typical single particle (inset in Fig. 3a, Fig. s4c). The STEM-HAADF image (Fig. 4b) for one single CoZn@ $\mathrm{Zn}_{(1-\mathrm{x})} \mathrm{Co}_{\mathrm{x}} \mathrm{O}_{\mathrm{y}}$ particle suggests a graduallychanged contrast from the inner part to the out surface. Similar as those synthesized by all NMP-phased process, analysis on the element content changes from the inner part to the surface (Fig. 4c) implys a $\mathrm{Zn}$ alloyed Co-rich core and a Co-doping $\mathrm{ZnO}$ shell by considering the formation mechanism and EDX result for the whole particles (Fig. s3c-ii).

The full XPS spectrum for CoZn@Zn $n_{(1-x)} \mathrm{Co}_{\mathrm{x}} \mathrm{O}_{\mathrm{y}} \mathrm{NPs}$ (Fig. s5c) confirms the existence of Co, Zn, O, C, B and N in these NPs. The 
Table 1 | Synthesis conditions of nanohybrids

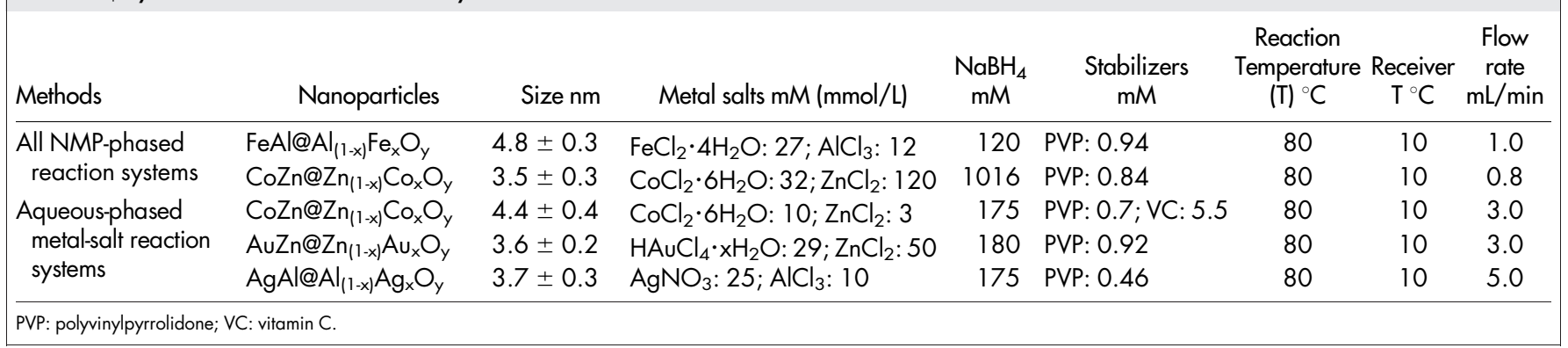

high-resolution XPS spectrum for $\mathrm{Zn}$ in $\mathrm{CoZn} @ \mathrm{Zn}_{(1-\mathrm{x})} \mathrm{Co}_{\mathrm{x}} \mathrm{O}_{\mathrm{y}}$ nanohybrids (Fig. 4d) also shows two asymmetric peaks centered at $1023.1 \mathrm{eV}$ and $1046.1 \mathrm{eV}$, which can be indexed as $\mathrm{Zn} \mathrm{2p3/2}$ and $\mathrm{Zn} 2 \mathrm{p} 1 / 2$, respectively. The blueshift peak at $1023.1 \mathrm{eV}$ by comparing with the peak at $1021.7 \mathrm{eV}$ for $\mathrm{Zn} 2 \mathrm{p} 3 / 2$ and the blue shift Co $2 \mathrm{p} 3 / 2$ peak at $781.5 \mathrm{eV}$ (from $780.5 \mathrm{eV}$ ) in the high energy resolution XPS of $\mathrm{Co}$ (Fig. 4e) indicate the existence of $\mathrm{Co} / \mathrm{Co}^{2+}$ doped $\mathrm{ZnO}$, such as $\mathrm{ZnCoO}$ or $\mathrm{ZnCoO}_{2}$. The two distinct shake up peaks at the high-energy side of Co 2p3/2 and Co 2p1/2 peaks indicate that most of cobalt in $\mathrm{Zn}_{(1-x)} \mathrm{Co}_{\mathrm{x}} \mathrm{O}_{\mathrm{y}}$ is bivalent, or mainly $\mathrm{ZnCoO}_{2}$. However, $\mathrm{ZnCo}_{2} \mathrm{O}_{4}$ cannot be excluded according to the XRD characterization (Fig. 4f). The asymmetric features of the BE peaks for $\mathrm{Zn}$ and Co also suggest existence of metallic $\mathrm{Zn}$ (BE: $1021.8 \mathrm{eV}$ and $1044.2 \mathrm{eV}$ ), metallic Co (BE: $778.4 \mathrm{eV}), \mathrm{Zn}(\mathrm{OH})$ and $\mathrm{Zn}-\mathrm{N}$ bonds, $\mathrm{CoO}$ and $\mathrm{Co}(\mathrm{OH})_{2}$. According to the HRTEM and STEM characterization, these metallic metals can be mainly from the $\mathrm{Zn}$ alloyed Co cores and those compounds can be only from the Co-doping $\mathrm{ZnO}$ coatings.

The XRD pattern of these NPs (Fig. 4f) shows similar but more distinct featured peaks than those CoZn@Zn $n_{(1-x)} \mathrm{Co}_{\mathrm{x}} \mathrm{O}_{\mathrm{y}} \mathrm{NPs}$ synthesized by all NMP-phased process, possibly due to the increased size. Two broad and weak peaks at $44.5^{\circ}$ and $72.5^{\circ}$ represent the (111) plane and the (220) plane of fcc Co or the (002) plane and the (110) plane of hcp Co, respectively. Other two broad peaks and shoulders at $34.7^{\circ}, 36.0^{\circ}, 37.1^{\circ}$ and $61.4^{\circ}$ represent the (002) plane of wurtzite $\mathrm{ZnO}$ possibly doped by $\mathrm{Co}^{2+} / \mathrm{Co}\left(\mathrm{ZnCoO}_{2} / \mathrm{ZnCoO}\right)$, the (311) plane of cubic $\mathrm{ZnCo}_{2} \mathrm{O}_{4}$, the (101) plane of wurtzite $\mathrm{ZnO}$ possibly doped by $\mathrm{Co}^{2+} / \mathrm{Co}$ and the (511) plane of cubic $\mathrm{ZnCo}_{2} \mathrm{O}_{4}$, respectively, according to the EDX characterization (Fig. s3c-ii) for the whole particles and the formation mechanism. By recalling the STEM-HADDF and XPS analysis, XRD results indicate the existence of $\mathrm{ZnCo}_{2} \mathrm{O}_{4}$ at out- a
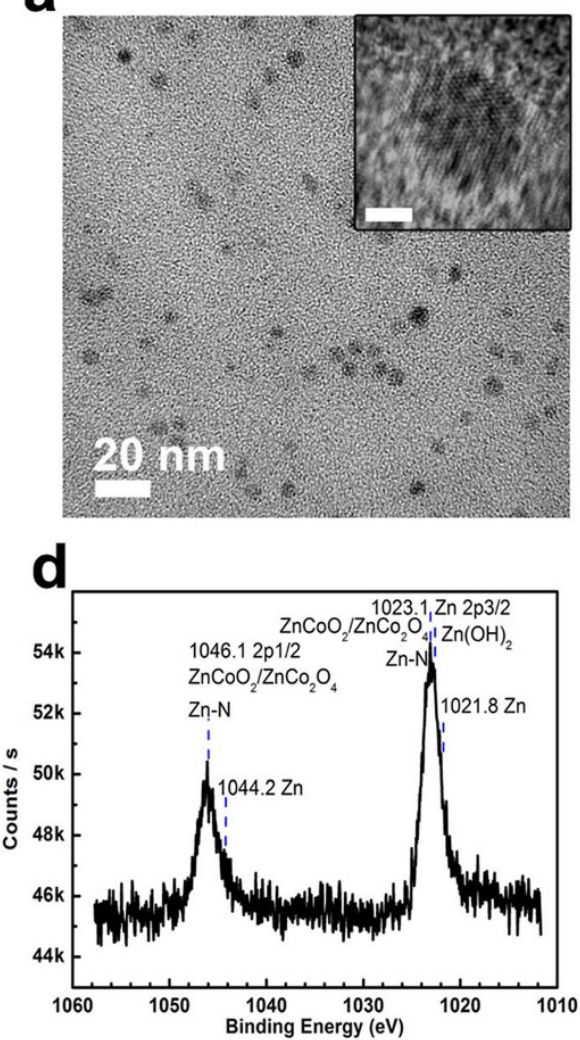

b

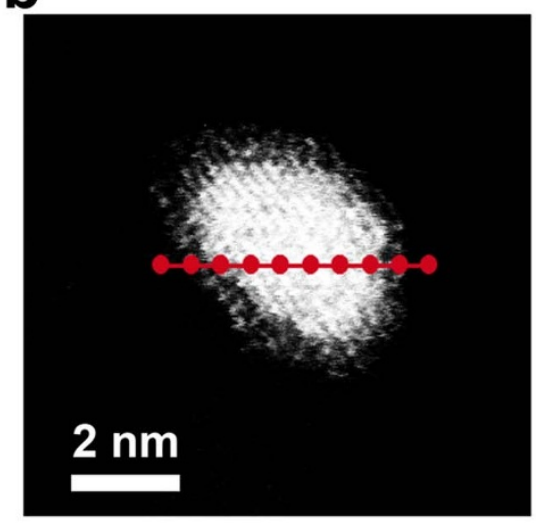

e

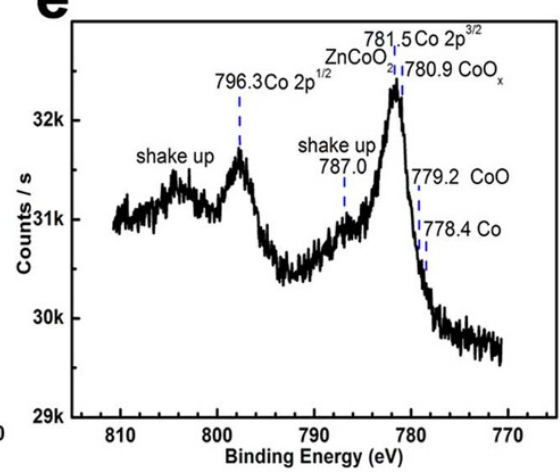

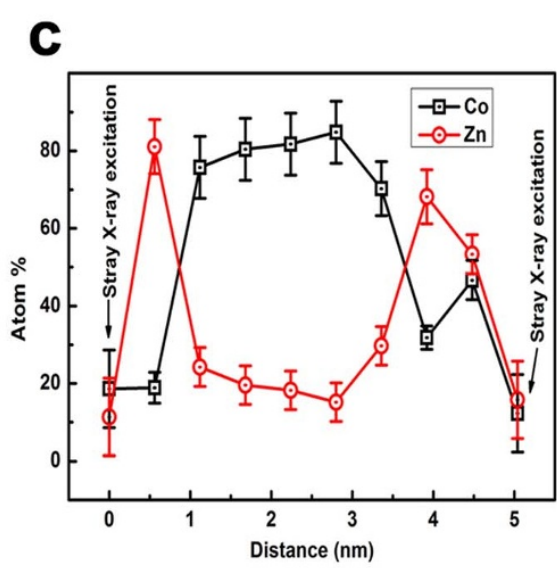

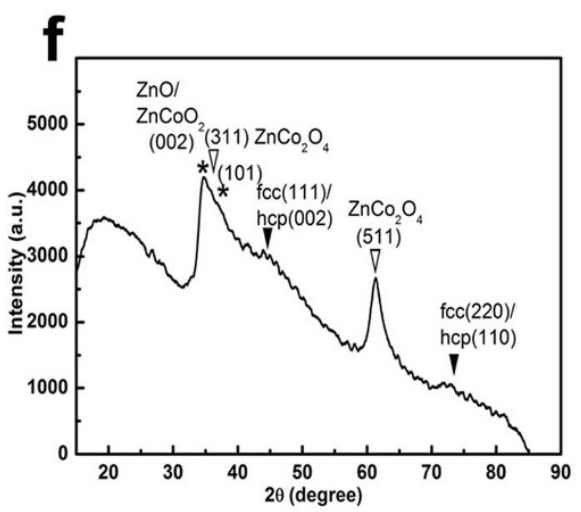

Figure 4 | Wide-viewed TEM image (a), HR-TEM image of one single particle (a: inset, scale bar: $2 \mathrm{~nm}$ ), STEM-HAADF image of one single particle (b), point-by-point EDX scanning of one single particle (c), high energy resolution XPS for Zn (d), high energy resolution XPS for Co (e) and XRD (f) of CoZn@Zn $\mathbf{Z}_{(1-x)} \mathrm{Co}_{\mathrm{x}} \mathrm{O}_{\mathrm{y}}$ nanohybrids synthesized using aqueous-phased metal salt reaction systems. JCPDS No for XRD analysis: fcc Co, 15-0806; hcp Co, 05-0727; wurtzite $\mathrm{ZnO}, 36-1451$; spinel $\mathrm{ZnCo}_{2} \mathrm{O}_{4}, 23-1390$. In XRD (vi), $\nabla$ : the corresponding metallic phases; $\nabla$ and *: the corresponding metal oxides. 
ermost layers and $\mathrm{ZnCoO} / \mathrm{ZnCoO}_{2}$ at sub-layers of the metal oxide coating.

Similar as those CoZn@ $\mathrm{Zn}_{(1-\mathrm{x})} \mathrm{Co}_{\mathrm{x}} \mathrm{O}_{\mathrm{y}}$ synthesized by all NMPphased reaction process, it can be reasonably concluded that these NPs are made of cobalt-rich fcc/hcp CoZn alloys as cores, and of Co/ $\mathrm{Co}^{2+}$ doped $\mathrm{ZnO}$ (e.g., $\mathrm{ZnCoO}$ or $\mathrm{ZnCoO}_{2}$ ) and $\mathrm{ZnCo}_{2} \mathrm{O}_{4}$ as surface coatings according to the above analysis by TEM, HRTEM, STEMHADDF, XPS, XRD and EDX. The shell is made of a $\mathrm{Co} / \mathrm{Co}^{2+} / \mathrm{Co}^{3+}$ gradient-doping $\mathrm{ZnO}$ surface coating. In addition, some $\mathrm{Co} / \mathrm{Co}^{2+} /$ $\mathrm{Co}^{3+}$ doped $\mathrm{Zn}(\mathrm{OH})_{2}$ or $\mathrm{CoOOH}$ and $\mathrm{Co}(\mathrm{OH})_{2}$ and some $\mathrm{B}_{2} \mathrm{O}_{3}$ may be included in the shell and the metallic alloy core may include some B.

Similar as the all NMP-phased reaction systems, the new aqueousphased metal salt reaction system also shows its generality by the successful synthesis of other nanohybrids with alloyed cores and gradient-doping shells at a high flow rate no less than $3.0 \mathrm{~mL} / \mathrm{min}$, such as CoAl@Al $\mathrm{Al}_{(1-\mathrm{x})} \mathrm{Co}_{\mathrm{x}} \mathrm{O}_{\mathrm{y}}, \mathrm{FeAl} @ \mathrm{Al}_{(1-\mathrm{x})} \mathrm{Fe}_{\mathrm{x}} \mathrm{O}_{\mathrm{y}}, \mathrm{FeZn} @ \mathrm{Zn}_{(1-\mathrm{x})} \mathrm{Fe}_{\mathrm{x}} \mathrm{O}_{\mathrm{y}}(\mathrm{x}<$ 1). Realization of gradient nanohybrids using aqueous-phased metal salts boosts our faith to extend our strategy into other kinds of nanohybrids synthesis that may have more challenge to overcome crystal lattice mismatch, such as plasmonic-dielectric ( $\mathrm{AgAl} @ \mathrm{Al}_{(1-\mathrm{x})} \mathrm{Ag}_{\mathrm{x}} \mathrm{O}_{\mathrm{y}}$ ) or plasmonic-semiconductor $\left(\mathrm{AuZn} @ \mathrm{Zn}_{(1-\mathrm{x})} \mathrm{Au}_{\mathrm{x}} \mathrm{O}_{\mathrm{y}}\right)$ nanomaterials.

Figure 5a show the TEM image of $\mathrm{AgAl} @ \mathrm{Al}_{(1-\mathrm{x})} \mathrm{Ag}_{\mathrm{x}} \mathrm{O}_{\mathrm{y}} \mathrm{NPs}$ synthesized by aqueous-phased metal salt reaction system, suggesting a narrow size distribution. Statistics on their diameters give a mean diameter of $3.7 \pm 0.3 \mathrm{~nm}$ (Fig. s3d-i). Their HRTEM images clearly show the highly-crystallized nature of these NPs with distinct coreshell morphology (inset: Fig. 5a) and crystal lattice difference (Fig. s4d). In order to further prove their core-shell structures, the STEMHAADF image and point-by-point EDX characterization for some typical particles were performed. Figure $5 \mathrm{~b}$ is the STEM-HAADF image of one single particle, which clearly showing the different contrast between the center and the surface layer of this particle. The element contents of Ag and Al by point-by-point EDX scanning (Fig. 5c) show a distinct gradient structure with decreased Ag/Al ratio from the center to the out surface of this particle. This result indicates a typical gradient core-shell structure: $\mathrm{A} \mathrm{Al}$ alloying $\mathrm{Ag}$ core (about $75 \% \mathrm{Ag}$ and $25 \% \mathrm{Al}$ ), an $\sim 0.5 \mathrm{~nm}$ thick $\mathrm{Al}_{2} \mathrm{O}_{3}$ interlayer with Ag dopant gradually-decreasing from $75 \%$ to $50 \%$ and an $\sim 1.2 \mathrm{~nm}$ thick $\mathrm{Ag}$ doping $\mathrm{Al}_{2} \mathrm{O}_{3}$ surface coating with the $\mathrm{Ag} / \mathrm{Al}$ ratio kept at about $50 \%$.

The full XPS spectrum for AgAl@ $\mathrm{Al}_{(1-\mathrm{x})} \mathrm{Ag}_{\mathrm{x}} \mathrm{O}_{\mathrm{y}}$ nanohybrids (Fig. s5d) confirms the existence of $\mathrm{Ag}, \mathrm{Al}, \mathrm{O}, \mathrm{C}, \mathrm{B}$ and $\mathrm{N}$ in these NPs. Figure $5 \mathrm{~d}$ is the high energy resolution XPS spectrum for $\mathrm{Al}$ in $\mathrm{AgAl} @ \mathrm{Al}_{(1-\mathrm{x})} \mathrm{Ag}_{\mathrm{x}} \mathrm{O}_{\mathrm{y}}$ nanohybrids, showing two distinct broad peaks with multi-shoulders. These peaks and shoulders can be indexed as the binding energy of metallic $\mathrm{Al} 2 \mathrm{p} 3$ at $72.7 \mathrm{eV}$, metallic $\mathrm{Al} 2 \mathrm{p} 1$ at $73.2 \mathrm{eV}, \mathrm{Al}-\mathrm{N}$ at $73.9 \mathrm{eV}, \mathrm{Al}_{2} \mathrm{O}_{3}$ or $\mathrm{Al}(\mathrm{OH})_{3} / \mathrm{AlOOH}$ at $74.3-$ $74.4 \mathrm{eV}$ and $\mathrm{AlO}_{\mathrm{x}}$ at $75.4 \mathrm{eV}$. The high energy resolution XPS spectrum for $\mathrm{Ag}$ in $\mathrm{AgAl} @ \mathrm{Al}_{(1-\mathrm{x})} \mathrm{Ag}_{\mathrm{x}} \mathrm{O}_{\mathrm{y}}$ nanohybrids (Fig. 5e) shows two pronunced peaks at $367.3 \mathrm{eV}$ and $373.3 \mathrm{eV}$, which can be indexed as $\mathrm{Ag} \mathrm{3d} 1 / 2$ and $\mathrm{Ag} 3 \mathrm{~d} 3 / 2$, respectively, indicating the existence of $\mathrm{Ag}_{2} \mathrm{O}$ in the NPs. The high energy resolution XPS spectrum for Ag also suggests existence of metallic Ag in the surface coatings of these NPs, as evidenced by the weak peak at $370.8 \mathrm{eV}$ for $\mathrm{Ag} 3 \mathrm{~d}$ and the shoulders at $374.9 \mathrm{eV}$ for $\mathrm{Ag} 3 \mathrm{~d} 3,368.7 \mathrm{eV}$ for $\mathrm{Ag} 3 \mathrm{~d} 5 / 2$ and $366.9 \mathrm{eV}$ for Ag $2 \mathrm{~s}$. Recalling the STEM-HAADF image of one single particle and the EDX analysis for these NPs ensemble (Fig. s3d-ii), these results clearly suggest the gradient structure in these NPs, including $\mathrm{Al}$ alloyed metallic $\mathrm{Ag}$ cores, the $\mathrm{Ag} / \mathrm{Ag}^{+}$doped $\mathrm{Al}_{2} \mathrm{O}_{3}$ interlayer with the $\mathrm{Ag} / \mathrm{Ag}^{+}$dopant decreasing from the core to the surface coating, and the $\mathrm{AlAgO}_{2}$ at the outmost surface, which can be a

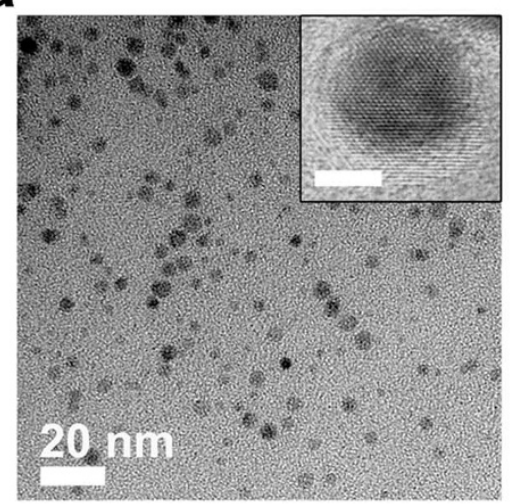

d

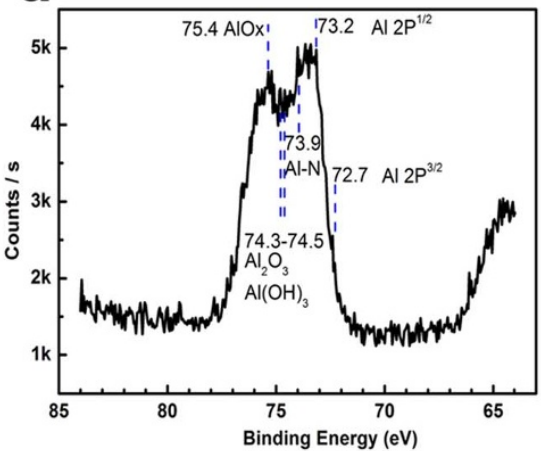

b
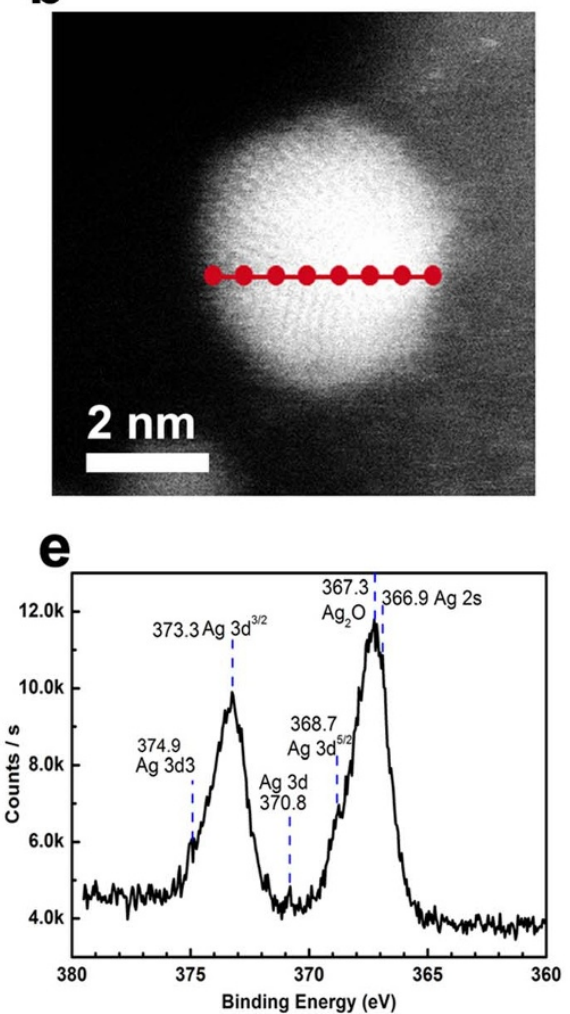
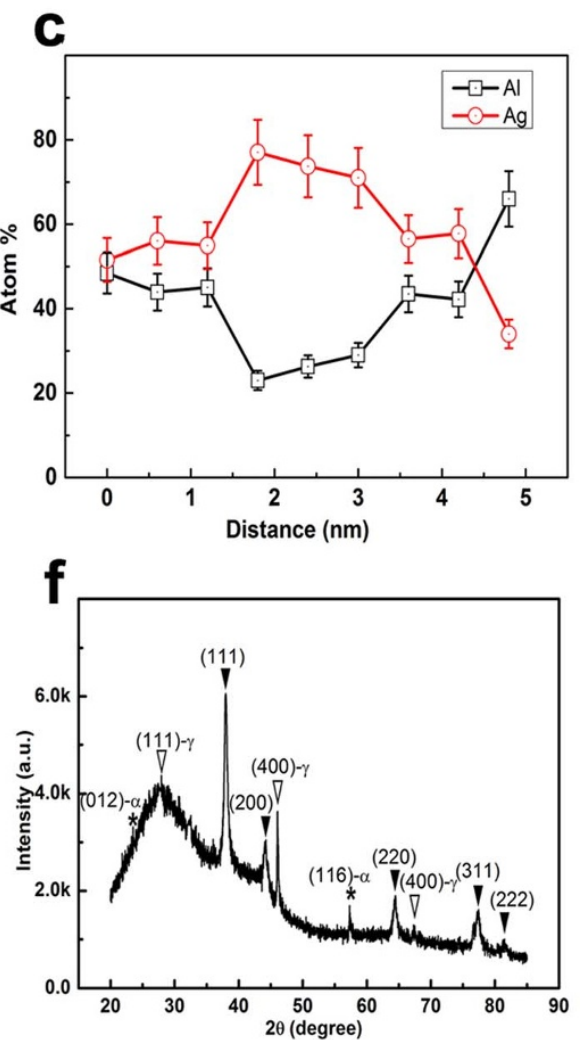

Figure 5 Wide-viewed TEM image (a), HR-TEM image of one single particle (a: inset, scale bar: $2 \mathrm{~nm}$ ), STEM-HAADF image of one single particle (b), point-by-point EDX scanning of one single particle (c), high energy resolution XPS for Al (d), high energy resolution XPS for Ag (e) and XRD (f) for $\mathrm{AgAl} @ \mathrm{Al}_{(1-\mathrm{x})} \mathrm{Ag}_{\mathrm{x}} \mathrm{O}_{\mathrm{y}}$ nanohybrids synthesized using aqueous-phased metal salt reaction systems. JCPDS No for XRD analysis: fcc Ag, 15-0806; fcc Al, 04-0787; $\alpha-\mathrm{Al}_{2} \mathrm{O}_{3}, 46-1212 ; \gamma-\mathrm{Al}_{2} \mathrm{O}_{3}, 10-0425 ;$. In XRD (f), $\boldsymbol{\nabla}$ : the corresponding metallic phases; $\nabla$ and *: the corresponding metal oxides. 
further confirmed by XRD analysis (Fig. 5f). Of course, the existence of Ag doping $\mathrm{Al}_{2} \mathrm{O}_{3}$ near the metallic $\mathrm{AgAl}$ cores cannot be excluded due to the sharply increased Ag content.

Their XRD peaks (Fig. 5f) at $38.0^{\circ}, 44.1^{\circ}, 64.4^{\circ}, 77.4^{\circ}$ and $81.6^{\circ}$ show slight variation from those of the standard fcc Ag and fcc Al. They can be reasonably indexed as the inflection from the (111), (200), (220), (311) and (222) planes of Al alloyed fcc Ag, respectively, according to XPS analysis. Peaks at $32.5^{\circ}, 46.1^{\circ}$ and $67.4^{\circ}$ can be indexed as the (111), (220) and (400) planes of Ag doping $\gamma$ $\mathrm{Al}_{2} \mathrm{O}_{3}$, peaks at $23.3^{\circ}$ and $57.3^{\circ}$ can be indexed as the (012) and (116) planes of $\mathrm{Ag}$ doping rhombohedral $\alpha-\mathrm{Al}_{2} \mathrm{O}_{3}$ and the broad peak at $27.9^{\circ}$ can be indexed from amorphous $\mathrm{Al}(\mathrm{OH})_{3} / \mathrm{AlOOH}$ by combination of the above XPS analysis. Therefore, it can be reasonably concluded that these nanohybrids are made of AgAl alloy as cores, $\mathrm{Ag} / \mathrm{Ag}^{+}$gradient-doping $\gamma-/ \alpha-\mathrm{Al}_{2} \mathrm{O}_{3}$ and some amorphous $\mathrm{Al}(\mathrm{OH})_{3} / \mathrm{AlOOH}$ as surface coatings according to the XRD, XPS, STEM-HAADF analysis and the EDX for the whole NPs (Fig. s3d-ii).

Figure 6a show the TEM image of AuZn@Zn $n_{(1-x)} \mathrm{Au}_{\mathrm{x}} \mathrm{O}_{\mathrm{y}} \mathrm{NPs}$ synthesized by the aqueous-phased metal salt process, suggesting a uniform size distribution. Statistics on their diameters give a mean diameter of $3.6 \pm 0.2 \mathrm{~nm}$ (Fig. s3e-i). Their HRTEM images clearly show the highly-crystallzed nature of these NPs with distinct coreshell morphology (Fig. 6a: inset) and crystal lattice difference (Fig. s4e). In order to confirm their core-shell structures, the STEMHAADF image and point-by-point EDX characterization for some typical particles are performed. Figure $6 \mathrm{~b}$ is the STEM-HAADF image of one single particle, which clearly shows the different contrast between the center and the surface layer of this particle. The element contents of $\mathrm{Au}$ and $\mathrm{Zn}$ recorded by point-by-point EDX scanning (Fig. 6c) show a distinct gradient structure with $\mathrm{Au} / \mathrm{Zn}$ ratio decreasing from the core to the particle surface. This result indicates a typical gradient core-shell structure: a $\mathrm{Zn}$ alloying $\mathrm{Au}$ core (about $80 \% \mathrm{Au}$ and $20 \% \mathrm{Zn}$ in the core), an $\sim 1.0 \mathrm{~nm}$ thick Au doped $\mathrm{ZnO}$ interlayer with Au dopant gradually-decreasing from $80 \%$ to $\sim 30 \%$ and an $\sim 0.5 \mathrm{~nm}$ thick Au doping $\mathrm{ZnO}$ surface coating with the $\mathrm{Au} / \mathrm{Zn}$ ratio kept from $4 / 6$ to $3 / 7$.

Similar as other nanohybrids, the full XPS spectrum for AuZn@ $\mathrm{Zn}_{(1-\mathrm{x})} \mathrm{Au}_{\mathrm{x}} \mathrm{O}_{\mathrm{y}}$ nanohybrids (Fig. s5e) confirms the existence of $\mathrm{Au}$, $\mathrm{Zn}, \mathrm{O}, \mathrm{C}, \mathrm{B}$ and $\mathrm{N}$ in these NPs. The high energy resolution XPS spectrum for $\mathrm{Zn}$ in $\mathrm{AuZn} @ \mathrm{Zn}_{(1-\mathrm{x})} \mathrm{Au}_{\mathrm{x}} \mathrm{O}_{\mathrm{y}}$ nanohybrids (Fig. 6d) shows two distinct peaks at $1021.8 \mathrm{eV}$ and $1044.5 \mathrm{eV}$, representing $\mathrm{Zn} \mathrm{2p3/2} \mathrm{and} \mathrm{Zn} \mathrm{2p1/2.} \mathrm{According} \mathrm{to} \mathrm{the} \mathrm{symmetry} \mathrm{peak} \mathrm{feature} \mathrm{and}$ the peak shift to high energy, which are very different from those asymmetry feature in other nanohybrids (e.g., CoZn@Zn $\mathrm{Z}_{(1-\mathrm{x})} \mathrm{Co}_{\mathrm{x}} \mathrm{O}_{\mathrm{y}}$ ), $\mathrm{ZnO}$ doped by Au should be dominant in the top surface of these NPs. Only trace of metallic $\mathrm{Zn}$ exists in the surface coating according to the peak at $9.7 \mathrm{eV}$ for $\mathrm{Zn} 3 \mathrm{~d}$ binding energy and other peaks, such as $\mathrm{Zn}_{\text {loss }}$ binding energy at $102.9 \mathrm{eV}, \mathrm{Zn} 3 \mathrm{~s}$ binding energy at $139.5 \mathrm{eV}$ and $\mathrm{Zn} 2 \mathrm{~s}$ binding energy at $1195.4 \mathrm{eV}$ (Fig. s5e). The high energy resolution XPS spectrum for $\mathrm{Au}$ in $\mathrm{AuZn} @ \mathrm{Zn}_{(1-\mathrm{x})} \mathrm{Au}_{\mathrm{x}} \mathrm{O}_{\mathrm{y}}$ nanohybrids (Fig. 6e) gives two peaks at $83.3 \mathrm{eV}$ and $87.4 \mathrm{eV}$, representing $\mathrm{Au} 4 \mathrm{f} 7 / 2$ and $\mathrm{Au} 4 \mathrm{f} 5 / 2$, respectively, which can be attributed from the metallic Au alloy cores. The other two shoulders at $88.5 \mathrm{eV}$ and $89.0 \mathrm{eV}$ in the high energy broad peak can be addressed as the binding energy for $\mathrm{Au}_{2} \mathrm{O}_{3}$ and the binding energy for $\mathrm{Au}(\mathrm{OH})$, respectively.

Distinct peaks (solid triangles) in their XRD pattern (Fig. 4b-v) at $38.1^{\circ}, 44.2^{\circ}$ and $77.3^{\circ}$, can be indexed as the reflection from the (111), (200) and (311) planes of Zn slightly-alloyed fcc Au, respectively, by recalling the above XPS analysis. Others strong peaks (void triangles) a

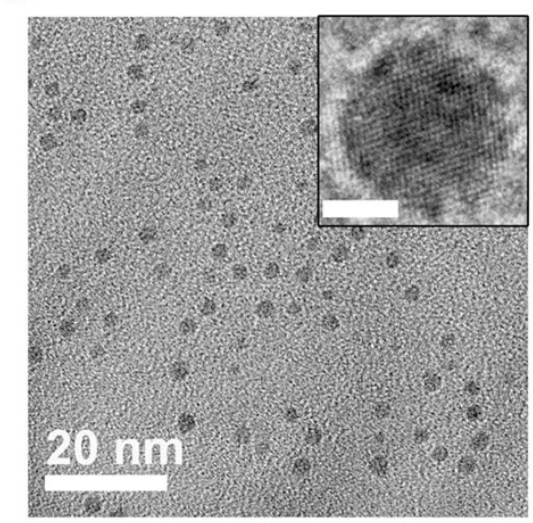

d

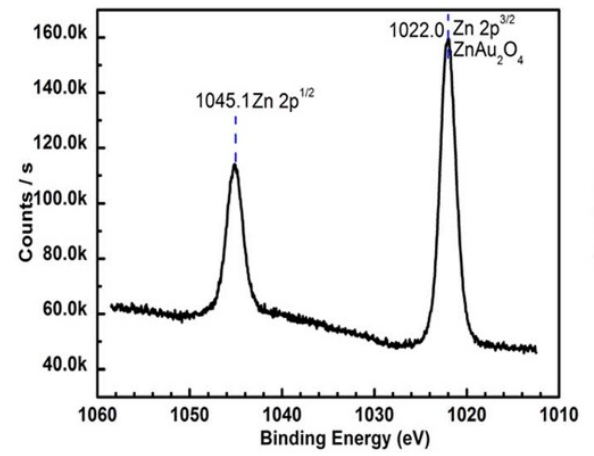

b

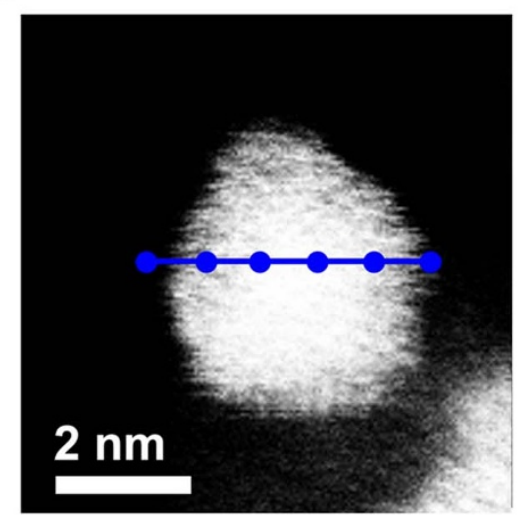

e

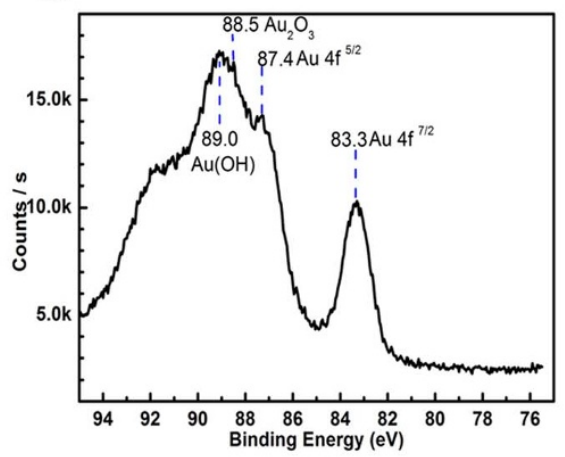

C

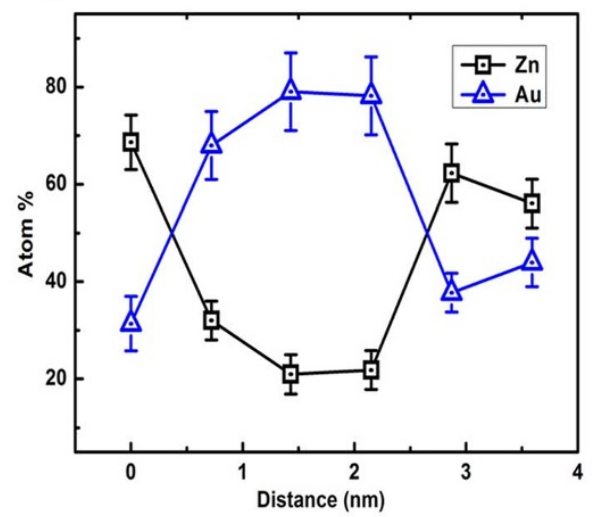

f

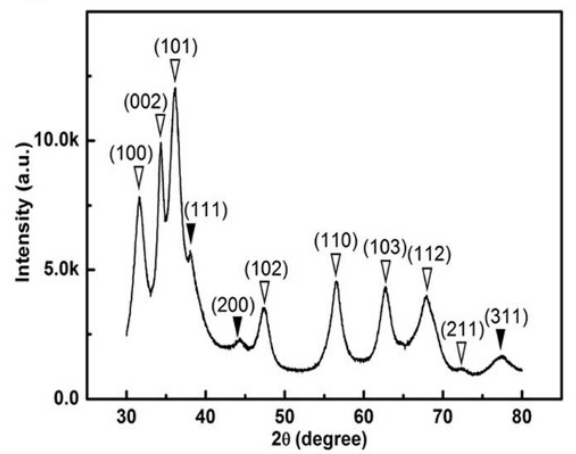

Figure 6 Wide-viewed TEM image (a), HR-TEM image of one single particle (a: inset, scale bar: 2 nm), STEM-HAADF image of one single particle (b), point-by-point EDX scanning of one single particle (c), high energy resolution XPS for Zn (d), high energy resolution XPS for Au (e) and $\mathrm{XRD}$ (f) for AuZn@Zn $\mathrm{Zn}_{(1-\mathrm{x})} \mathrm{Au}_{\mathrm{x}} \mathrm{O}_{\mathrm{y}}$ nanohybrids synthesized using aqueous-phased metal slat reaction systems. JCPDS No for XRD analysis: fcc Au, 05-0727; wurtzite $\mathrm{ZnO}, 36-1451$. In XRD (f), $\nabla$ : the corresponding metallic phases; $\nabla$ : the corresponding metal oxides. 
in their XRD pattern at $31.7^{\circ}, 34.4^{\circ}, 36.1^{\circ}, 47.4^{\circ}, 56.6^{\circ}, 62.8^{\circ}, 67.9^{\circ}$ and $72.4^{\circ}$ can be indexed as the reflections from the (100), (002), (101), (102), (110), (103), (112), (211) planes of wurtzite $\mathrm{ZnO}$ doped by $\mathrm{Au} / \mathrm{Au}^{3+}$ according to the XPS analysis.

Combination of their TEM, HRTEM, STEM-HAADF, XPS and EDX analysis for the single NPs and NPs assemble (Fig. s3e-ii), it can be confidently deduced that cores of AuZn@ $\mathrm{Zn}_{(1-\mathrm{x})} \mathrm{Au}_{\mathrm{x}} \mathrm{O}_{\mathrm{y}}$ nanohybrids are made of $\mathrm{Zn}$ slightly-alloyed $\mathrm{Au}$ and shells of AuZn@ $\mathrm{Zn}_{(1-\mathrm{x})} \mathrm{Au}_{\mathrm{x}} \mathrm{O}_{\mathrm{y}}$ nanohybrids are mainly made of $\mathrm{Au} / \mathrm{Au}^{3+}$ gradientdoping $\mathrm{ZnO}$ (e.g., $\mathrm{ZnAuO}, \mathrm{ZnAu}_{2} \mathrm{O}_{4}$ ) possibly mixed with some $\mathrm{Au}(\mathrm{OH})$.

These nanohybrids with alloy cores and gradient shells preserve unique magnetic and optical peoperties. The room temperature hysteresis loops (RTHLs) and thermal-magnetism measurements (zerofield cooling (ZFC) and field-cooling (FC) curves with an applied field of $100 \mathrm{Oe})$ of $\mathrm{FeAl} @ \mathrm{Al}_{(1-\mathrm{x})}(\mathrm{Fe})_{\mathrm{x}} \mathrm{O}_{\mathrm{y}}$ and $\mathrm{CoZn} @ \mathrm{Zn}_{(1-\mathrm{x})} \mathrm{Co}_{\mathrm{x}} \mathrm{O}_{\mathrm{y}}$ NPs are plotted in Fig. 7. Their magnetic parameters are summarized in Table 2. The RTHLs of these nanohybrids (Fig. 7a, 7b) show the mono-phase nominal ferromagnetic feature with non-zero coercivities and small biases $(\sim 2 \mathrm{Oe})$. The reduced coercivities by comparing with those Co and Fe NPs less than $5 \mathrm{~nm}$ (Table 2) ${ }^{43}$ suggest that gradient doping $\mathrm{ZnO}$ or $\mathrm{Al}_{2} \mathrm{O}_{3}$ coatings on the Co or Fe cores can increase the magnetic dipole interaction among particles more greatly than the magnetic anisotropy, leading to the small magnetic reverse barrier, or reduced $\mathrm{H}_{\mathrm{c}}{ }^{9,17,38,43}$. Clearly, the small exchange biases in these nanohybrids can be attributed to the exchange coupling between the cores and the surface metal oxide coatings by recalling their gradient core-shell structures. Their FC-ZFC curves show the highly bifurcated thermo-magnetism (Fig. 7c), or unmatched defreezing temperatures $\left(\mathrm{T}_{\mathrm{f}}\right)$ and merging temperature $\left(\mathrm{T}_{\mathrm{m}}\right)$, suggesting an enhanced magnetic anisotropy in these magnetic cores due to the gradient surface coatings. The higher $\mathrm{T}_{\mathrm{f}}$ values for all nanohybrids than those of pure Co and Fe NPs indicate a strong pining interface indeed introduced between the cores and the surface coatings made of doped metal oxides. By considering the size and magnetic anisotropy effects on the $\mathrm{T}_{\mathrm{f}}\left(\mathrm{T}_{\mathrm{f}}=K_{u} V / 25 k_{B} ; K_{u}\right.$ : the magnetic anisotropy constant; $V$ : the mean volume of the particles), the $K_{u}$ can be enhanced about 2.6 times for the $\mathrm{FeAl}_{0} @ \mathrm{Al}_{(1-\mathrm{x})} \mathrm{Fe}_{\mathrm{x}} \mathrm{O}_{\mathrm{y}} \mathrm{NPs}$ (mean core diameter: $3 \mathrm{~nm}$ ) compared with the Fe NPs. As for CoZn@Zn $\mathrm{Zn}_{(1-\mathrm{x})} \mathrm{Co}_{\mathrm{x}} \mathrm{O}_{\mathrm{y}} \mathrm{NPs}$, the $K_{u}$ can be enhanced about 1.4 times for NPs (mean core diameter: $2.5 \mathrm{~nm}$ ) synthesized by all NMPphased reaction systems and about 1.7 times for NPs (core diameter: $2.5 \mathrm{~nm}$ ) synthesized by aqueous-phased metal salt reaction systems. In addition, the exchange coupling effect between cores and shells on the $K_{u}$ cannot be excluded, which can reduce $K_{u}$.

The optical properties of these nanohybrids having $\mathrm{Zn}_{(1-x)} \mathrm{Co}_{\mathrm{x}} \mathrm{O}_{\mathrm{y}}$, $\mathrm{Ag}$, or $\mathrm{Au}$ components were examined by UV-vis (Fig. 8a) and photoluminescence spectroscopy (Fig. 8b). Generally, these nanohybrids with $\mathrm{Zn}_{(1-x)} \mathrm{Co}_{\mathrm{x}} \mathrm{O}_{\mathrm{y}}$ exhibit distinct blue shift UV absorbance and multi-peak feature as compared to that of bulk $\mathrm{ZnO}(\sim 379 \mathrm{~nm})$, which can be attributed to the bandgap shifts and different types of defects in $\mathrm{ZnO}$ caused by different doping and/or core effects. The CoZn@Zn $n_{(1-x)} \mathrm{Co}_{\mathrm{x}} \mathrm{O}_{\mathrm{y}}$ NPs synthesized using all NMP-phased reaction systems show multi-peak UV-vis absorbance (Fig. 8a-i): peaks at $328 \mathrm{~nm}$ and $379 \mathrm{~nm}$ are from $\mathrm{ZnO}$, while peaks at $574 \mathrm{~nm}$ and $735 \mathrm{~nm}$ possibly are from defects caused by Co dopants. The $\mathrm{CoZn} @ \mathrm{Zn}_{(1-\mathrm{x})} \mathrm{Co}_{\mathrm{x}} \mathrm{O}_{\mathrm{y}}$ (Fig. 8a-ii) nanohybrids synthesized by aqueous-phased metal-salt reaction systems only show 2 peaks at $323 \mathrm{~nm}$ and $817 \mathrm{~nm}$ and one weak shoulder at $492 \mathrm{~nm}$. This result suggests that more complicated doping effects on $\mathrm{ZnO}$ can be realized by using all NMP-phased reaction systems than by aqueous-phase metal salt reaction systems. The $\mathrm{AgAl} @ \mathrm{Al}_{(1-\mathrm{x})} \mathrm{Ag}_{\mathrm{x}} \mathrm{O}_{\mathrm{y}}$ (Fig. 8a-iv) and AuZn@Zn $n_{(1-x)} A_{u_{x}} \mathrm{O}_{y}$ NPs (Fig. 8a-iii) show distinct UV-vis absorbance at $406 \mathrm{~nm}$ and $514 \mathrm{~nm}$, ascribed to the localized surface Plasmon resonance (LSPR) of Ag and Au cores affected by the thin Ag doping $\mathrm{Al}_{2} \mathrm{O}_{3}$ or $\mathrm{Au}$ doping $\mathrm{ZnO}$ shells, respectively. In addition,
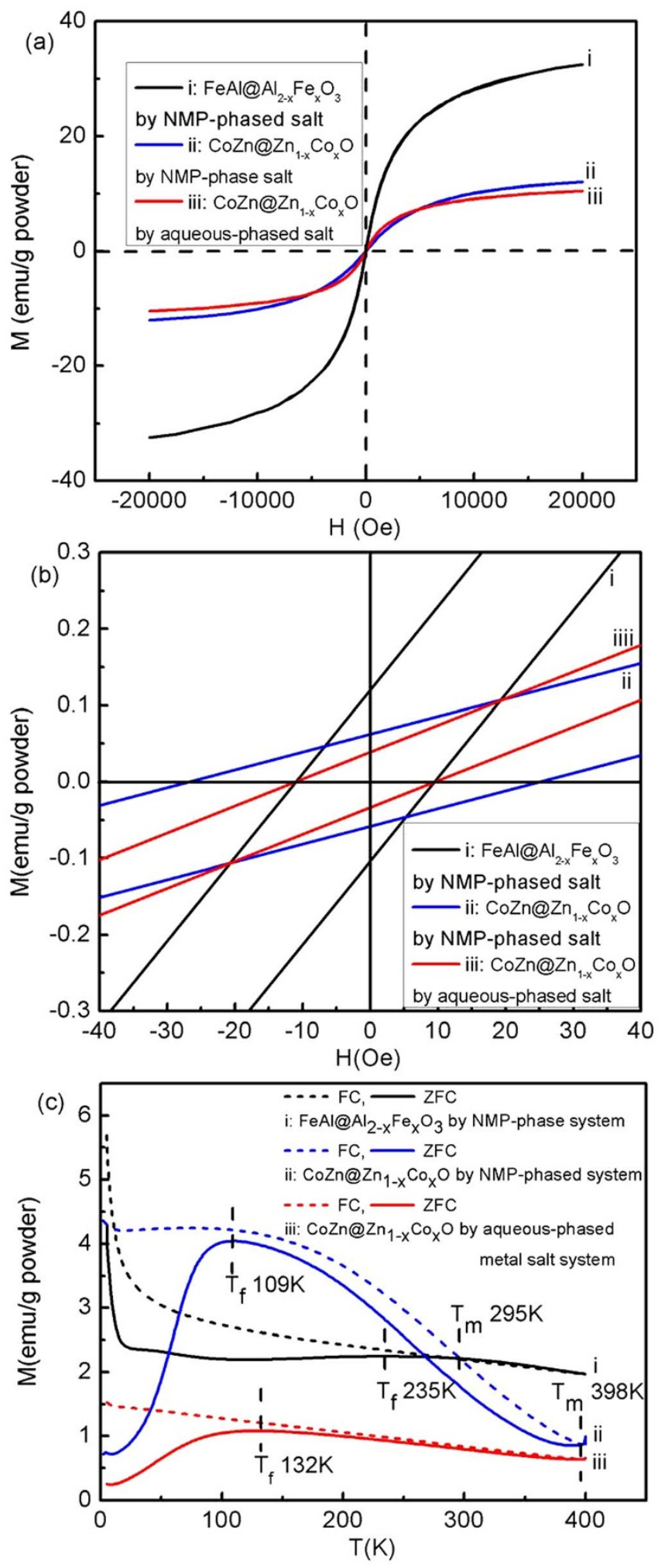

Figure $7 \mid$ Full-range (a) and magnified-center (b) of room temperature hysteresis loop and the thermo-magnetism curves (c) (ZFC: zero-field cooling; FC: field cooling) of (i) $\mathrm{FeAl} @ \mathrm{Al}_{(1-\mathrm{x})} \mathrm{Fe}_{\mathrm{x}} \mathrm{O}_{\mathrm{y}}$ and (ii) $\mathrm{CoZn} @$ $\mathrm{Zn}_{(1-\mathrm{x})} \mathrm{Co}_{\mathrm{x}} \mathrm{O}_{\mathrm{y}}$ nanohybrids synthesized using all NMP-phased reaction systems and (iii) $\mathrm{CoZn} @ \mathrm{Zn}_{(1-\mathrm{x})} \mathrm{Co}_{\mathrm{x}} \mathrm{O}_{\mathrm{y}}$ nanohybrids synthesized using aqueous-phase metal salt reaction systems.

UV-vis absorbance of AuZn@ $\mathrm{Zn}_{(1-\mathrm{x})} \mathrm{Au}_{\mathrm{x}} \mathrm{O}_{\mathrm{y}}$ NPs also shows two peaks at $294 \mathrm{~nm}$ and $350 \mathrm{~nm}$, which may be the defect excitation in $\mathrm{ZnO}$ affected by the LSPR of Au cores. 
Table 2 | Magnetic properties of nanohybrids

\begin{tabular}{|c|c|c|c|c|c|c|}
\hline Method & Sample & Size nm & \multicolumn{2}{|c|}{${ }^{a} \mathrm{H}_{c}, \mathrm{Oe}$} & ${ }^{b} T_{f} K$ & ${ }^{\mathrm{c}} \mathrm{T}_{\mathrm{m}} \mathrm{K}$ \\
\hline $\begin{array}{l}\text { All NMP phased reaction systems } \\
\text { Aqueous phased metal salt reaction systems } \\
\text { All NMP phased reaction systems }\end{array}$ & $\begin{array}{l}\mathrm{FeAl} @ \mathrm{Al}_{(1-x)} \mathrm{Fe}_{x} \mathrm{O}_{y} \\
\mathrm{CoZn} @ \mathrm{Zn}_{(1-x)} \mathrm{Co}_{x} \mathrm{O}_{y} \\
\mathrm{CoZn} @ \mathrm{Zn}_{(1-x)} \mathrm{Co}_{x} \mathrm{O}_{y} \\
{ }^{\mathrm{d}} \mathrm{Fe} \\
{ }^{\mathrm{d}} \mathrm{Co}\end{array}$ & $\begin{array}{l}4.8 \pm 0.3 \\
3.5 \pm 0.3 \\
4.4 \pm 0.4 \\
3.5 \pm 0.3 \\
2.5 \pm 0.2\end{array}$ & $\begin{array}{l}-11 \\
-27 \\
-11 \\
-37 \\
-35\end{array}$ & $\begin{array}{r}9 \\
25 \\
9 \\
37 \\
34\end{array}$ & $\begin{array}{r}235 \\
109 \\
132 \\
141 \\
73\end{array}$ & $\begin{array}{l}295 \\
398 \\
398 \\
348 \\
146\end{array}$ \\
\hline
\end{tabular}

aHc: coercivity;

${ }^{{ }^{6} T_{f}: ~ t h e ~ f r e e z i n g ~ t e m p e r a t u r e ~ a b o v e ~ w h i c h ~ t h e ~ N P s ~ g r a d u a l l y ~ s h i f t ~ f r o m ~ c l u s t e r s-g l a s s ~(C G) ~ l i k e ~ s t a t e ~ t o ~ t h e ~ f e r r o m a g n e t i c ~(F M) ~ s t a t e ; ~}$

${ }^{c} T_{m}$ : the merging temperature for zero-field-cooling curves $\left(M_{Z F C}(T)\right)$ and field-cooling curves $\left(M_{F C}(T)\right.$ ), indicating that the NPs are in the same FM state for ZFC and FC processes above that temperature; dData from X Shen, et al., RSC Advances 4, 34179(2014).

The photoluminescence (PL) spectrum of the CoZn@Zn $\mathrm{Zn}_{(1-\mathrm{x})} \mathrm{Co}_{\mathrm{x}} \mathrm{O}_{\mathrm{y}}$ nanohybrids synthesized using all NMP-phased reaction systems exhibits one distinct extinction PL peaks at $353 \mathrm{~nm}$ and one strong shoulder at $475 \mathrm{~nm}$ (Fig. 8b-i). The PL spectrum of these CoZn@ $\mathrm{Zn}_{(1-\mathrm{x})} \mathrm{Co}_{\mathrm{x}} \mathrm{O}_{\mathrm{y}}$ nanohybrids synthesized using aqueous-phased metalsalt reaction systems gives blue shift ultra-violet extinction at $\sim 346 \mathrm{~nm}$ and a suppressed blue extinction at $\sim 475 \mathrm{~nm}$ (Fig. 8bii), possibly due to the reduced doping effect by considering their UVvis spectra and reaction mechanisms. This can be further convinced by the much reduced peak at $470 \mathrm{~nm}$ for $\mathrm{AuZn} @ \mathrm{Zn}_{(1-\mathrm{x})} \mathrm{Au}_{\mathrm{x}} \mathrm{O}_{\mathrm{y}} \mathrm{NPs}$ (Fig. 8b-iii) synthesized using aqueous-phased metal salt reaction systems since it may be more difficult for Au doping into $\mathrm{ZnO}$ shells than Co. Results on their UV-vis and PL spectra provide additional evidence for the formation of hybrid nanostructures with controlled surface coatings.

\section{Discussion}

Generally, we have successful lly expanded SPMPs to a hybrid microfluidic and batch-cooling process for the synthesis of gradient coreshell nanohybrids based on the core alloying and shell gradient-doping strategy realized by coupled competitive reducing-nucleation

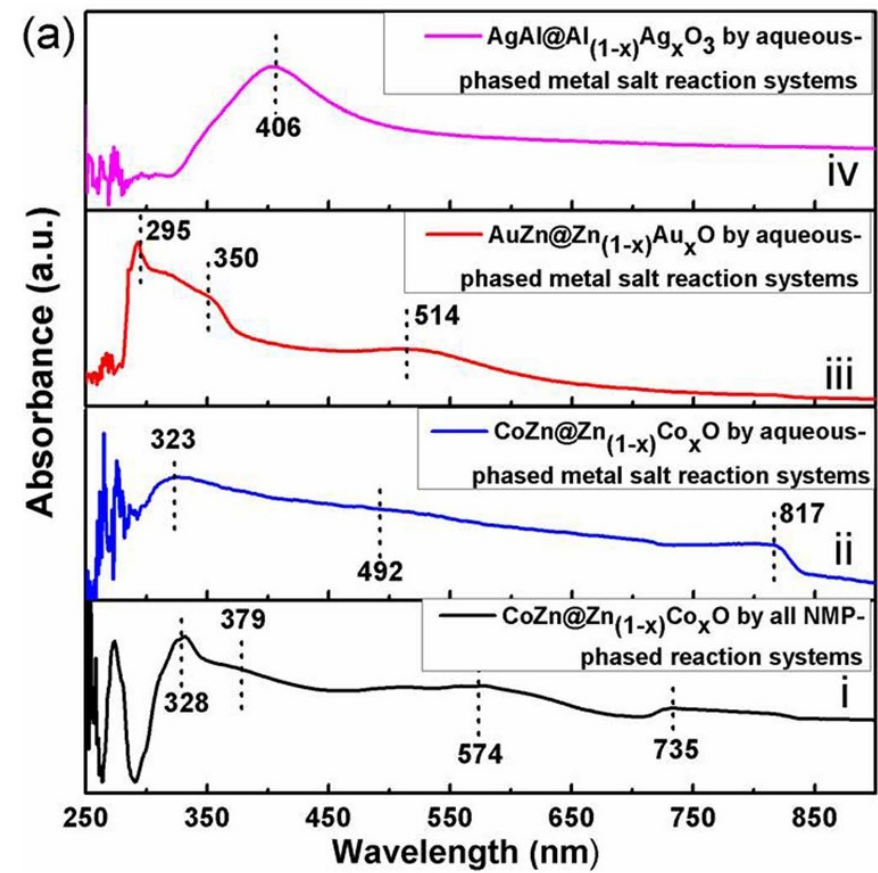

and precipitation reactions. The crystal lattice mismatch between different components in nanohybrids can be efficiently avoided by utilizing this strategy. The coupled competitive reactions can be wellcontrolled by the types of mixed metal salts and bi-channel solvents in the microfluidics for the desired compositions and structures in metallic alloy cores and mixed metal oxide surface coatings. Most importantly, each stage in the nanoparticle formation can be spatiotemperally separated along the microfluidic channel and the rapid cooling receiver. Particularly, the sudden burst of transient nucleation to form alloy cores and the surface precipitation on preformed cores and the following growth stage can be efficiently separated from Ostwald ripening stage along the microfluidic channel. Thus, sizes, compositions and structures in alloy cores and surface coatings can be well-controlled at the desired growth stage. The crystal lattice mismatch between different components in nanohybrids can be efficiently avoided by utilizing the strategy of core alloying and gradient-doping the second metal oxide coating with the primary metal. Consequently, varieties of nanohybrids with metal alloys as cores and gradient-doping metal oxides as shells have been successfully synthesized, such as magneto-dielectrics (FeAl@ $\left.\mathrm{Al}_{(1-\mathrm{x})} \mathrm{Fe}_{\mathrm{x}} \mathrm{O}_{\mathrm{y}}, \mathrm{CoAl} @ \mathrm{Al}_{(1-\mathrm{x})} \mathrm{Co}_{\mathrm{x}} \mathrm{O}_{\mathrm{y}}, \mathrm{CoFeAl} @ \mathrm{Al}_{(1-\mathrm{x})}(\mathrm{CoFe})_{\mathrm{x}} \mathrm{O}_{\mathrm{y}}\right)$, mag-

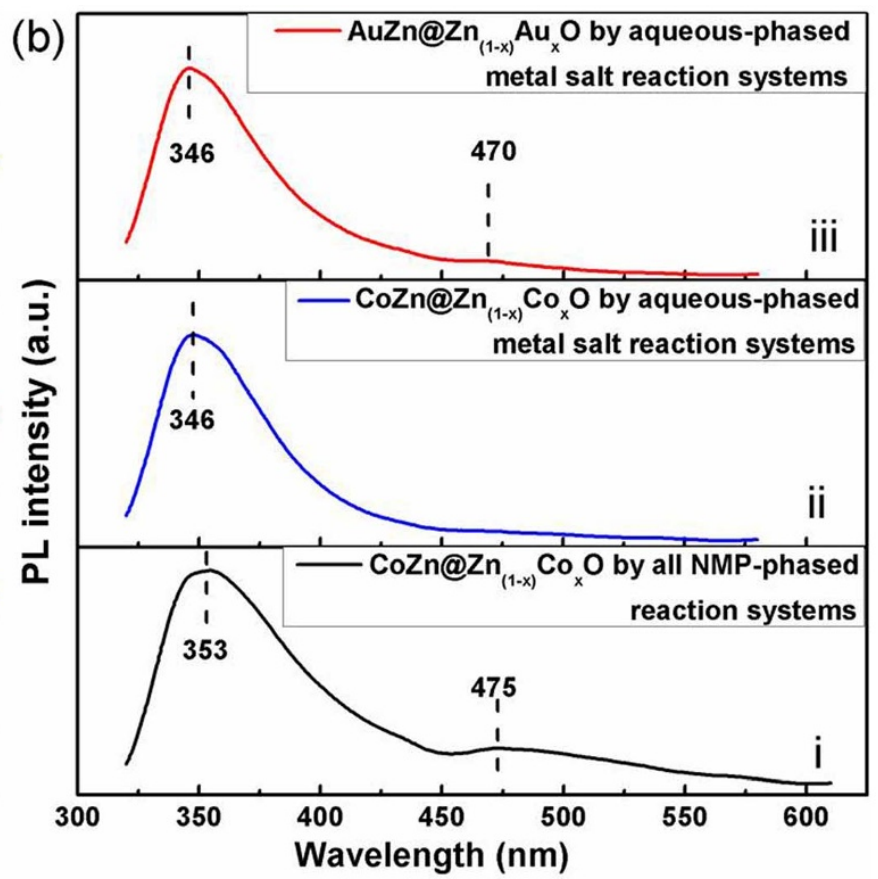

Figure 8 $\mid$ (a) UV-vis spectra of CoZn@ $\mathrm{Zn}_{(1-\mathrm{x})} \mathrm{Co}_{\mathrm{x}} \mathrm{O}_{\mathrm{y}}$ (i) nanohybrids synthesized using using all NMP-phased reaction systems, and CoZn@ $\mathrm{Zn}_{(1-\mathrm{x})} \mathrm{Co}_{\mathrm{x}} \mathrm{O}_{\mathrm{y}}$ (ii), $\mathrm{AuZn} @ \mathrm{Zn}_{(1-\mathrm{x})} \mathrm{Au}_{\mathrm{x}} \mathrm{O}_{\mathrm{y}}$ (iii) and $\mathrm{AgAl} @ \mathrm{Al}_{(1-\mathrm{x})} \mathrm{Ag}_{\mathrm{x}} \mathrm{O}_{\mathrm{y}}$ (iv) nanohybrids synthesized aqueous-phased metal salt reaction systems.

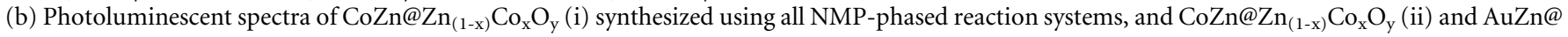
$\mathrm{Zn}_{(1-\mathrm{x})} \mathrm{Au}_{\mathrm{x}} \mathrm{O}_{\mathrm{y}}$ (iii) nanohybrids synthesized using aqueous-phased metal salt reaction systems. 
Table 3 | Theoretical (feeding content) and experimental (by EDX) metal atom ratios of nanohybrids and surface metal atom ratios in nanohybrids by XPS

\begin{tabular}{|c|c|c|c|c|c|}
\hline Method & Sample & Size, nm & $\begin{array}{l}\text { Theoretical } \\
\text { atomic ratio }\end{array}$ & $\begin{array}{c}\text { Atomic ratio of } \\
\text { whole particles by EDX }\end{array}$ & $\begin{array}{c}\text { Top surface atomic } \\
\text { ratio by XPS }\end{array}$ \\
\hline $\begin{array}{l}\text { All NMP-phased reaction systems } \\
\text { Aqueous-phased metal salt reaction systems }\end{array}$ & 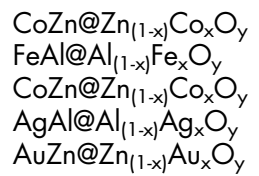 & $\begin{array}{l}3.5 \pm 0.3 \\
4.8 \pm 0.3 \\
4.4 \pm 0.4 \\
3.7 \pm 0.3 \\
3.6 \pm 0.2\end{array}$ & $\begin{array}{l}\text { Co/Zn: } 21 / 79 \\
\text { Fe/Al: } 76 / 24 \\
\text { Co/Zn: } 77 / 23 \\
\text { Ag/Al: } 71 / 29 \\
\text { Au/Zn: } 37 / 64\end{array}$ & $\begin{array}{l}\text { Co/Zn: } 43 / 57 \\
\text { Fe/Al: } 82 / 18 \\
\text { Co/Zn: } 23 / 77 \\
\text { Ag/Al: } 38 / 62 \\
\text { Au/Zn: } 18 / 82\end{array}$ & $\begin{array}{l}\text { Co/Zn: } 31 / 69 \\
\text { Fe/Al: } 34 / 66 \\
\text { Co/Zn: } 20 / 80 \\
\text { Ag/Al: 5/95 } \\
\text { Au/Zn: 5/95 }\end{array}$ \\
\hline
\end{tabular}

neto-semiconductors (FeZn@Zn $\left.\mathrm{Zn}_{(1-\mathrm{x})} \mathrm{Fe}_{\mathrm{x}} \mathrm{O}_{\mathrm{y}}, \quad \mathrm{CoZn} @ \mathrm{Zn}_{(1-\mathrm{x})} \mathrm{Co}_{\mathrm{x}} \mathrm{O}_{\mathrm{y}}\right)$, plasmon-semiconductors ( $\mathrm{AuZn} @ \mathrm{Zn}_{(1-\mathrm{x})} \mathrm{Au}_{\mathrm{x}} \mathrm{O}_{\mathrm{y}}$ ) and plasmon-dielectrics $\left(\mathrm{AgAl} @ \mathrm{Al}_{(1-\mathrm{x})} \mathrm{Ag}_{\mathrm{x}} \mathrm{O}_{\mathrm{y}}\right)($ all $\mathrm{x}<1)$. Results on nanohybrids except these in this article will be published in our future articles.

The coupled competitive reducing-nucleation and precipitation reactions can be performed either by all NMP-phased reaction systems or by aqueous-phased metal-salt reaction systems for a wide range of composition and structure control in these nanohybrids. The metal ratios in some nanohybrids measured by EDX were summarized in Table 3. Comparing with the theoretical values calculated by the metal content used in the feeds, ratios in these nanohybrids synthesized by all NMP-phased reaction systems are usually higher than the theoretical values, while it is on the contrary in those nanohybrids synthesized by aqueous-phased metal salt reaction systems. This result can be elucidated by the additional enhanced precipitation reactions of rx-14 and $\mathrm{rx}-15$ besides $\mathrm{rxl} \sim \mathrm{rx} 13^{43}$, leading to rapid formation of lots of $\mathrm{Zn}(\mathrm{OH})_{2}$ or $\mathrm{Al}(\mathrm{OH})_{3}$. These $\mathrm{Al}(\mathrm{OH})_{3}$ or $\mathrm{Zn}(\mathrm{OH})_{2}$ will precipitate on the cores to form relatively thick coatings, passivating the growth of metallic cores and finally leading to the reduced core contents (or the reduced primary metal content) in these nanohybrids. As $\mathrm{Zn}(\mathrm{OH})_{2}$ or $\mathrm{Al}(\mathrm{OH})_{3}$ are dehydrated to lose $\mathrm{H}_{2} \mathrm{O}$, nanohybrids having $\mathrm{Al}_{2} \mathrm{O}_{3}$ or $\mathrm{ZnO}$ surface coatings will be formed and more $\mathrm{Zn}$ and $\mathrm{Al}$ contents can be introduced into metal oxide shells of nanohybrids than those formed in all NMP-phased reaction systems. Theoretically, this result may be related to their atomic ratios for binary alloy formation and the different precipitation rates under different reaction environments, which will be discussed in our future articles.

$$
\begin{gathered}
\mathrm{Zn}^{2+}+2 \mathrm{OH}^{-} \rightarrow \mathrm{Zn}(\mathrm{OH})_{2} \\
\mathrm{Al}^{3+}+3 \mathrm{OH}^{-} \rightarrow \mathrm{Al}(\mathrm{OH})_{3}
\end{gathered}
$$

The primary metal to the second metal ratios in these nanohybrids calculated by XPS are also summarized in Table 3. As expected, these ratios are usually lower than the mean ratios in the whole nanohybrids measured by EDX since most surface coatings and only part of the metallic cores were included in the XPS measurement. This result provides additional evidence that the surface coatings are mainly made of primary metal doping second metal oxides and cores should be formed by the second metal alloying primary metal. The primary metal to the second metal ratio in $\mathrm{CoZn} @ \mathrm{Zn}_{(1-\mathrm{x})} \mathrm{Co}_{\mathrm{x}} \mathrm{O}_{\mathrm{y}}$ nanohybrids synthesized by aqueous-phased metal salt reaction systems is higher than those synthesized by all NMP-phased reaction systems even though the primary metal content used in all NMP-phased reaction systems is higher that that used in aqueous-phased metal salt reaction systems. This is consistent with the above analysis that aqueousphased metal salt reaction systems favor to the rapid formation of $\mathrm{Al}(\mathrm{OH})_{3}$ or $\mathrm{Zn}(\mathrm{OH})_{2}$ that can precipitate on the cores to form relatively thick coatings.

These nanohybrids shall preserve unique magnetic and/or optical properties due to the gradient-doping in shells and core alloying that can significantly affect their surface structures and the proximity effects among components. The structure (sizes, surface coatings) and composition differences in nanohybrids originated from two reaction systems affect their magnetic properties significantly.
According to the thermal magnetisms of CoZn@ $\mathrm{Zn}_{(1-\mathrm{x})} \mathrm{Co}_{\mathrm{x}} \mathrm{O}_{\mathrm{y}} \mathrm{NPs}$ (Table 2), the magnetic anisotropy in nanohybrids synthesized using aqueous-phased metal salt reaction systems is higher than those synthesized using all NMP-phased reaction systems. This result suggests that the rapid formation of surface oxides can greatly increase the surface pinning effect on magnetic cores and the interface canting effects between cores and surfaces. It is often evidenced by the chainlike nanoparticle assembles, as shown in Figure s6 using CoZn@ $\mathrm{Zn}_{(1-\mathrm{x})} \mathrm{Co}_{\mathrm{x}} \mathrm{O}_{\mathrm{y}}$ nanohybrids as example. The thermal magnetism and relative $\mathrm{K}_{\mathrm{u}}$ analyses of CoZn@ $@ \mathrm{Zn}_{(1-\mathrm{x})} \mathrm{Co}_{\mathrm{x}} \mathrm{O}_{\mathrm{y}}$ and FeAl@Al $\mathrm{Al}_{(1-\mathrm{x})} \mathrm{Fe}_{\mathrm{x}} \mathrm{O}_{\mathrm{y}}$ NPs suggest that $\mathrm{Al}_{2} \mathrm{O}_{3}$ coatings can produce higher surface pining and interface canting effect than $\mathrm{ZnO}$ coatings. This result enlights us a promise for the synthesis of ultra-small ferromagnetic nanoparticles used at high temperature for ultra-high density media (Tbits/inch ${ }^{2}$ ) by greatly enhancing their magnetic anisotropies. Indeed, we have synthesize FeAl@ $\mathrm{Al}_{(1-\mathrm{x})} \mathrm{Fe}_{\mathrm{x}} \mathrm{O}_{\mathrm{y}}$ and $\mathrm{CoAl} @ \mathrm{Al}_{(1-\mathrm{x})} \mathrm{Co}_{\mathrm{x}} \mathrm{O}_{\mathrm{y}} \mathrm{NPs}$ of about $3.0 \mathrm{~nm}$ with $\mathrm{T}_{\mathrm{f}}$ more than $300 \mathrm{~K}$ using aqueous-phased metal salt reaction systems, whose results will be published in our future articles.

Their UV-vis absorbances and photoluminescences indicate that the effective control of sizes and surface structures by suitable reaction routes in this article can conveniently tune their optical properties (Fig. 8). Generally, these nanohybrids with $\mathrm{Zn}_{(1-\mathrm{x})} \mathrm{Co}_{\mathrm{x}} \mathrm{O}_{\mathrm{y}}$ exhibit distinct blue shift UV absorbances compared with the bulk $\mathrm{ZnO}(\sim 377 \mathrm{~nm})$. Less types of defects can be introduced into $\mathrm{Zn}_{(1-\mathrm{x})} \mathrm{Co}_{\mathrm{x}} \mathrm{O}_{\mathrm{y}}$ by all NMP-phased reaction systems than by aqueous-phase reaction systems possibly due to the less Co dopant content in $\mathrm{Zn}_{(1-\mathrm{x})} \mathrm{Co}_{\mathrm{x}} \mathrm{O}_{\mathrm{y}}$ coatings. $\mathrm{ZnO}$ or $\mathrm{Al}_{2} \mathrm{O}_{3}$ coatings can influence their surface dielectric constants of $\mathrm{AgAl} @ \mathrm{Al}_{(1-\mathrm{x})} \mathrm{Ag}_{\mathrm{x}} \mathrm{O}_{\mathrm{y}}$ and $\mathrm{AuZn} @$ $\mathrm{Zn}_{(1-\mathrm{x})} \mathrm{Au}_{\mathrm{x}} \mathrm{O}_{\mathrm{y}} \mathrm{NPs}$ (usually higher than water). UV-vis results on the newly synthesized $\mathrm{AgAl} @ \mathrm{Al}_{(1-\mathrm{x})} \mathrm{Ag}_{\mathrm{x}} \mathrm{O}_{\mathrm{y}}$ and $\mathrm{Ag} \mathrm{NPs}(2.4 \pm 0.2 \mathrm{~nm}$, Fig. s7) suggest that the ultra-thin $(\sim 1 \mathrm{~nm}) \mathrm{Al}_{(1-\mathrm{x})} \mathrm{Ag}_{\mathrm{x}} \mathrm{O}_{\mathrm{y}}$ coatings and $\mathrm{Al}$ alloying do not significantly affect the LSPR peak of such tiny $\mathrm{Ag}$ nanocrystals. However, UV-vis results on the newly synthesized AuZn@Zn $\mathrm{Zn}_{(1-\mathrm{x})} \mathrm{Au}_{\mathrm{x}} \mathrm{O}_{\mathrm{y}} \mathrm{NPs}$ and Au NPs (3.5 $\pm 0.3 \mathrm{~nm}$, Fig. s7) suggest that the ultra-thin $(<1 \mathrm{~nm}) \mathrm{Zn}_{(1-\mathrm{x})} \mathrm{Au}_{\mathrm{x}} \mathrm{O}_{\mathrm{y}}$ coatings and $\mathrm{Zn}$ alloying can produce a blue shift of the LSPR peak in such tiny $\mathrm{Au}$ nanocrystals.

The core alloying and surface coating with different doping-metal types and contents also endow these nanohybrids with unique PLs. It is seen that all the spectra have a distinct peak of the intrinsic emission originated from the excitonic recombination in the UV region, corresponding to near-band-edge emission of zinc oxide, and/or a deep level emission peak in the visible region, corresponding to the intrinsic defect-related band. PL peaks in the UV region (346 $353 \mathrm{~nm}$ ) and in the blue region ( $470 \mathrm{~nm}$ or $475 \mathrm{~nm}$ ) show blue-shift by comparing with the ZnO NPs $(\sim 376 \mathrm{~nm} \text { and } \sim 525 \mathrm{~nm})^{48,49}$. The peak at the blue region (indicating the defect emission) for CoZn@ $\mathrm{Zn}_{(1-\mathrm{x})} \mathrm{Co}_{\mathrm{x}} \mathrm{O}_{\mathrm{y}}$ nanohybrids synthesized by aqueous-phased metal salt reaction systems disappears. It can be reasonably explained by the greatly-reduced content of the primary metal in the metal oxide surface coating (XPS data in Table 3) synthesized using aqueousphased metal-salt reaction systems since the deposition rates of $\mathrm{ZnO}$ on preformed cores can be significantly enhanced in the reaction system with high-water content ( $\mathrm{rx}-14)$. However, the blue emission can still be observed in the nanohybrids synthesized using aqueous- 


\begin{tabular}{|c|c|c|c|c|c|c|}
\hline \multirow[b]{2}{*}{ No } & \multirow[b]{2}{*}{ Nanoparticles } & \multicolumn{5}{|c|}{ Solubility in solvents } \\
\hline & & $\begin{array}{l}\mathrm{H}_{2} \mathrm{O} \\
\text { (a) }\end{array}$ & $\begin{array}{l}\text { NMP } \\
\text { (b) }\end{array}$ & $\begin{array}{l}\text { Chlorobenzene } \\
\text { (c) }\end{array}$ & $\begin{array}{l}\text { Chloroform } \\
\text { (d) }\end{array}$ & $\begin{array}{c}\text { Cyclohexane } \\
\text { (e) }\end{array}$ \\
\hline $\begin{array}{l}1 \\
2 \\
3 \\
4 \\
5\end{array}$ & 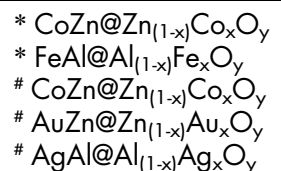 & $\begin{array}{l}>10 \mathrm{~g} / \mathrm{L} \\
>10 \mathrm{~g} / \mathrm{L} \\
>10 \mathrm{~g} / \mathrm{L} \\
>10 \mathrm{~g} / \mathrm{L} \\
>10 \mathrm{~g} / \mathrm{L}\end{array}$ & $\begin{array}{l}5-10 \mathrm{~g} / \mathrm{L} \\
>10 \mathrm{~g} / \mathrm{L} \\
>10 \mathrm{~g} / \mathrm{L} \\
>10 \mathrm{~g} / \mathrm{L} \\
>10 \mathrm{~g} / \mathrm{L}\end{array}$ & $\begin{array}{r}>10 \mathrm{~g} / \mathrm{L} \\
2-5 \mathrm{~g} / \mathrm{L} \\
2-5 \mathrm{~g} / \mathrm{L} \\
5-10 \mathrm{~g} / \mathrm{L} \\
>10 \mathrm{~g} / \mathrm{L}\end{array}$ & $\begin{array}{r}2-5 \mathrm{~g} / \mathrm{L} \\
2-5 \mathrm{~g} / \mathrm{L} \\
5-10 \mathrm{~g} / \mathrm{L} \\
>10 \mathrm{~g} / \mathrm{L} \\
>10 \mathrm{~g} / \mathrm{L}\end{array}$ & $\begin{array}{l}5-10 \mathrm{~g} / \mathrm{L} \\
5-10 \mathrm{~g} / \mathrm{L} \\
5-10 \mathrm{~g} / \mathrm{L} \\
>10 \mathrm{~g} / \mathrm{L} \\
>10 \mathrm{~g} / \mathrm{L}\end{array}$ \\
\hline
\end{tabular}

phased reaction system if the core metal Co is replaced by Au. The combined results on PLs of nanohybrids synthesized using all NMPphased reaction systems and aqueous-phased metal-salt reaction systems further enlight us that desired optical properties can be obtained by optimizing the composition and structure of cores and surface coatings. Indeed, greatly-enhanced blue emission were realized in FeZn@ $\mathrm{Zn}_{(1-\mathrm{x})} \mathrm{Co}_{\mathrm{x}} \mathrm{O}_{\mathrm{y}}$ nanohybrids synthesized by all NMPphased reaction systems, whose results will be published in our future articles.

These nanohybrids can be concentrated into slurry by centrifugal or magnets and dried to powder, which can be re-dispersed in high-polar solvents (e.g., NMP or $\mathrm{H}_{2} \mathrm{O}$ or chlorobenzene, Fig. s8a-c) and/or lowpolar solvents (e.g., chloroform or hexane, Fig. s8d-e) and show different colors. Their good solubilities in either polar or non-polar solvents (Table 4) endow them with broader applications than those NPs dissolved solely in polar or non-polar solvents. Applications on these kinds of NPs and other kinds of nanohybrids (FeZn@ $\mathrm{Zn}_{(1-\mathrm{x})} \mathrm{Co}_{\mathrm{x}} \mathrm{O}_{\mathrm{y}}, \mathrm{CoAl} @ \mathrm{Al}_{(1-\mathrm{x})} \mathrm{Co}_{\mathrm{x}} \mathrm{O}_{\mathrm{y}}, \mathrm{NiPt} @ \mathrm{Ni}_{(1-\mathrm{x})} \mathrm{Pt}_{\mathrm{x}} \mathrm{O}_{y}, \mathrm{AgRu} @ \mathrm{Ru}_{(1-\mathrm{x})} \mathrm{Ag}_{\mathrm{x}} \mathrm{O}_{2}$, $\mathrm{AuRu} @ \mathrm{Ru}_{(1-\mathrm{x})} \mathrm{Au}_{\mathrm{x}} \mathrm{O}_{\mathrm{y}}, \mathrm{FeMn} @ \mathrm{Mn}_{(1-\mathrm{x})} \mathrm{Fe}_{\mathrm{x}} \mathrm{O}_{\mathrm{y}}, \mathrm{FePt} @ \mathrm{FeOOH}$, etc.) synthesized by this strategy have been evaluated either as dual contrast agents for magnetic resonance imaging, or as energy storage materials for supercapacitors, or as optical emitters for optoelectronic devices, or as efficient catalysts for fuel cell, which will be discussed in our future articles. All these amazing applications and their unique physicochemical properties are, no doubt, due to the core alloying and shell gradient-doping in these nanohybrids. We believe that the developed sequenced reducing-nucleation and precipitation reaction in microfluidics shall provide us a general low cost scale out approach in the composition and structure controlled synthesis of nanohybrids with defined properties for advanced applications.

\section{Experiment Methods}

Assembly of the mixed microfluidic and batch-cooling process (hybrid process). The hybrid process was designed and assembled by connecting preheating stainless steel tubing coils, a transparent polymer tubing (e.g., Teflon) a Y connector (e.g. PEEK), the thermostatic tank 1 and 2 and the cooling tank for product receivers, as shown in Fig. s1.

Sequenced in-situ redox of metal ions and/or precipitation of metal oxides for hybrid nanoparticle synthesis. This synthesis method was developed by directly introducing the second-metal-salt with low standard electrode potential (i.e., $\mathrm{Zn}^{2+}$ $\mathrm{V}_{0}=-0.763 \mathrm{~V} ; \mathrm{Al}^{3+}: \mathrm{V}_{0}=-1.662 \mathrm{~V}$ ) into the primary-metal-salt solutions in the hybrid process. The detailed synthesis conditions for these hybrid NPs were summarized in Table 1 and Part I of SI.

Composition and structure characterization of nanoparticles. Morphologies, chemical compositions and lattice fringes of the nanowires were characterized by transmission electron microscopy (TEM; JOEL 2100F, $200 \mathrm{kV}$ ) equipped with energy-dispersive X-ray spectroscopy (EDX). The STEM-HAADF images ( $Z$ contrast image) were obtained on a Tecnai F20 $(200 \mathrm{kV})$ electron microscope equipped with EDX for point-by-point element analysis in single nanoparticles. The X-ray photoelectron spectroscopy (XPS) was used to determine the elemental composition as well as chemical and electronic state of the related elements in NPs by detecting their thin films. XPS measurements were carried out on an ESCALAB 250 Thermo Electron Corporation with an $\mathrm{Al} \mathrm{K \alpha} \mathrm{X-ray} \mathrm{source} \mathrm{(1486.6} \mathrm{eV} \mathrm{photons).} \mathrm{The}$ core-level signals were obtained at a photoelectron take-off angle of $45^{\circ}$ (with respect to the sample surface). The X-ray source was run at a power of $300 \mathrm{~W}$. The samples were mounted on the standard sample studs by means of double-sided adhesive tapes. The pressure in the analysis chamber was maintained at $2 \times 10^{-9} \mathrm{mbar}$ during each measurement. To compensate for surface charging effects, all binding energies (BE's) were referenced to the $\mathrm{C} 1 \mathrm{~s}$ hydrocarbon peak at $284.6 \mathrm{eV}$. Powder X-ray diffraction (XRD) data of samples were collected on a D/max 2200PC diffractometer ( $\mathrm{Cu} \mathrm{K} \alpha$ radiation, $\lambda=1.5418 \AA$, Rigaku, Japan).

Characterization of magnetic and optical property. The magnetic properties were evaluated by room temperature hysteresis loop (RMHL) and/or thermo-magnetism (ZFC: zero-field cooling; FC: field cooling) curves measured by MPPS (SQUID) (Quantum design) using an applied magnetic field of 100 Oe. The UV-vis spectra of samples in different solvents were measured by UV-vis spectroscopy (TU-1901, 190$900 \mathrm{~nm}$, Beijing Purkinje General Instrument Co., Ltd.) using the corresponding solvent as a reference. The photoluminescence (PL) property of samples was performed at room temperature by using 310 line of Xe 900 as the excitation source (FL-920, 450 W, Shanghai Qianxin Instrument Inc.).

1. Wu, B., Kuang, Y., Zhang, X. \& Chen, J. Noble metal nanoparticles/carbon nanotubes nanohybrids: Synthesis and applications. Nano Today 6, 75-90 (2011).

2. Huang, J. et al. Crystal engineering and SERS properties of $\mathrm{Ag}-\mathrm{Fe} 3 \mathrm{O} 4$ nanohybrids: from heterodimer to core-shell nanostructures. J. Mater. Chem. 21, 17930-17937 (2011).

3. Song, Y., Wang, Y., Li, B. B., Fernandes, C. \& Ruda, H. E. Interfacial Interaction Induced Self-Assembly of Nanoparticles into Superstructures. Nanoscale 5, 6779-6789 (2013).

4. Song, Y. et al. Magneto-Plasmons in Periodic Nanopore Structures. Sci. Rep. 4, 4991 (2014).

5. Belotelov, V. I. et al. Plasmon-mediated magneto-optical transparency. Nat. Commun. 4, 2128 (2013)

6. Belotelov, V. I. et al. Enhanced magneto-optical effects in magnetoplasmonic crystals. Nat. Nanotechnol. 6, 370-376 (2011).

7. Montero, M. I. et al. Nanostructures and the proximity effect. J. Phys. D: Appl. Phys. 35, 2398-2402 (2002)

8. Song, Y. et al. Magnetic and electric property evolution of amorphous cobalt-rich alloys driven by field annealing. J. Phys. D: Appl. Phys. 45, 225001 (2012).

9. Song, Y., Ding, J. \& Wang, Y. Shell Dependent Evolution of Optical and Magnetic Properties of Co@Au Core-shell Nanoparticles. J. Phys. Chem. C 116, 11343-11350 (2012).

10. Cozzoli, P. D., Pellegrino, T. \& Manna, L. Synthesis, properties and perspectives of hybrid nanocrystal structures. Chem. Soc. Rev. 35, 1195-1208 (2006).

11. Song, Y., Wang, Y. H., JI, S. \& Ding, J. Shell-Driven Fine Structure Transition in Co@Au Core-shell Nanoparticles. Nano-Micro Lett. 4, 235-242 (2012).

12. Sun, Q., Ren, Z., Wang, R., Wang, N. \& Cao, X. Platinum Catalyzed Growth of NiPt Hollow Spheres with an Ultrathin Shell. J. Mater. Chem. 21, 1925-1930 (2011).

13. Luo, J. et al. Homogeneous Photosensitization of Complex TiO2 Nanostructures for Efficient Solar Energy Conversion. Sci. Rep. 2, 451 (2012).

14. Song, Y., Sun, P., Henry, L. L. \& Sun, B. Mechanism for Structure and Performance Controlled Preparation of Thin Film Composite Membrane via Interfacial Polymerization. J. Membr. Sci. 251, 67-72 (2005).

15. Wang, L. et al. Hierarchical $\mathrm{SnO}_{2}$ Nanospheres: Bio-inspired Mineralization, Vulcanization, Oxidation Techniques, and the Application for NO Sensors. Sci. Rep. 3, 3500 (2013).

16. Li, S. et al. Controlled Hybridization of Sn-SnO2 Nanoparticles via Simple Programmed Microfluidic Processes for Tunable Ultraviolet and Blue Emissions. J. Mater. Chem. C 2, 7687-7694 (2014).

17. Song, Y. et al. In-situ Redox Microfluidic Synthesis of Core-Shell Nanoparticles and their Long-term Stability. J. Phys. Chem. C 117, 17274-17284 (2013).

18. Temnov, V. V. The marriage of plasmonics, magnetism, acoustics and ultrafast optics. Nat. Photonics 6, 728-736 (2012).

19. Jin, Y., Jia, C., Huang, S.-W., O’Donnell, M. \& Gao, X. Multifunctional nanoparticles as coupled contrast agents. Nat. Commun. 1, 41 (2010). 
20. Murphy, C. J. et al. Anisotropic Metal Nanoparticles: Synthesis, Assembly, and Optical Applications. J. Phys. Chem. B 109, 13857-13870 (2005).

21. Burda, C., Chen, X., Narayanan, R. \& El-Sayed, M. A. Chemistry and Properties of Nanocrystals of Different Shapes. Chem. Rev. 105, 1025-1102 (2005).

22. Bach, L. G., Islam, M. R., Lee, D. C. \& Lim, K. T. Poly(glycidyl methacrylate) grafted CdSe quantum dots by surface-initiated atom transfer radical polymerization: Novel synthesis, characterization, properties, and cytotoxicity studies. Appl. Surf. Sci. 283, 546-553 (2013).

23. Chen, G. et al. Interfacial Effects in Iron-Nickel Hydroxide-Platinum Nanoparticles Enhance Catalytic Oxidation. Science 344, 495-499 (2014).

24. Nan, F. et al. Manipulating Nonlinear Emission and Cooperative Effect of CdSe/ ZnS Quantum Dots by Coupling to a Silver Nanorod Complex Cavity. Sci. Rep. 4, 4839 (2014).

25. Farmer, J. A. \& Campbell, C. T. Ceria Maintains Smaller Metal Catalyst Particles by Strong Metal-Support Bonding. Science 329, 933-935 (2010).

26. deMello, A. J. Control and detection of chemical reactions in microfluidic systems. Nature 442, 394-402 (2006).

27. Song, Y., Kumar, C. S. S. R. \& Hormes, J. Microfluidic Synthesis of Nanomaterials. Small 4, 698-711 (2008).

28. Marre, S. \& Jensen, K. F. Synthesis of micro and nanostructures in microfluidic systems. Chem. Soc. Rev. 39, 1183-1202 (2010).

29. Nightingale, A. M. et al. Large-scale synthesis of nanocrystals in a multichannel droplet reactor. J. Mater. Chem. A 1, 4067-4076 (2013).

30. Song, Y. \& Henry, L. L. Nearly Monodispersion CoSm Nanoparticles Synthesized by a Microfluidic reactor. Nanoscale Res. Lett. 4, 1130-1134 (2009).

31. Carroll, K. J. et al. One-Pot Aqueous Synthesis of Fe and Ag Core/Shell Nanoparticles. Chem. Mater. 22, 6291-6296 (2010).

32. Boross, P. T., Dóra, B. Z., Kiss, A. R. \& Simon, F. A unified theory of spinrelaxation due to spin-orbit coupling in metals and semiconductors. Sci. Rep. 3, 3233 (2013).

33. Zhang, J., Tang, Y., Lee, K. \& Ouyang, M. Nonepitaxial growth of hybrid core-shell nanostructures with large lattice mismatches. Science 327, 1634-1638 (2010).

34. Seo, W. S. et al. $\mathrm{FeCo} /$ graphitic-shell nanocrystals as advanced magneticresonance-imaging and near-infrared agents. Nat. Mater. 5, 971-976 (2006).

35. Wang, X., Zhuang, J., Peng, Q. \& Yadong, L. A general strategy for nanocrystals synthesis. Nature 437, 121-124 (2005).

36. Khan, S. A. \& Duraiswamy, S. Controlling bubbles using bubbles-microfluidic synthesis of ultra-small gold nanocrystals with gas-evolving reducing agents. Lab Chip 12, 1807-1812 (2012)

37. Song, Y. et al. Investigations into sulfobetaine-stabilized $\mathrm{Cu}$ nanoparticle formation: toward development of a microfluidic synthesis. J. Phys. Chem. B 109, 9330-9338 (2005)

38. Song, Y., Henry, L. L. \& Yang, W. T. Stable Cobalt Amorphous Nanoparticles Formed by an In-situ Rapid Cooling Microfluidic Process. Langmuir 25, 10209-10217 (2009).

39. Abou-Hassan, A., Bazzi, R. \& Cabuil, V. Multistep Continuous-Flow Microsynthesis of Magnetic and Fluorescent g- $\mathrm{Fe}_{2} \mathrm{O}_{3} @ \mathrm{SiO}_{2}$ Core/Shell Nanoparticles. Angew. Chem. Int. Ed. 48, 7180-7183 (2009).

40. Park, J. I., Saffari, A., Kumar, S., Gunther, A. \& Kumacheva, E. Microfluidic synthesis of polymer and inorganic particulate materials. Annu. Rev. Mater. Res. 40, 415-443 (2010).

41. Erdem, E. Y., Cheng, J. C., Doyle, F. M. \& Pisano, A. P. Multi-Temperature Zone, Droplet-based Microreactor for Increased Temperature Control in Nanoparticle Synthesis. Small 10, 1076-1080 (2014).
42. Song, Y., Kumar, C. S. S. R. \& Hormes, J. Fabrication of SU-8 based microfluidic reactor on a PEEK substrate sealed by a "flexible semi-solid transfer" (FST) process. J. Micromech. Microeng. 14, 932-940 (2004).

43. Shen, X. et al. Spatiotemporal-Resolved Ultra-small Nanoparticle Synthesis via Simple Programmed Microfluidic Processes. RSC Adv. 4, 34179-34188 (2014).

44. James, B. D. \& Wallbride, M. G. H. Metal Tetrahydroborate. Vol. 11, 99-232 (Interscience Publisher, 1970).

45. Mochalov, K. N. \& Tremasov, N. V. Nature of the Products and Mechanism of the Reaction of BH4- with Heavy Metals. Vol. 36, 48-55 (Khim-Tekhn. Inst., 1967).

46. Kollonitsch, J. \& Fuchs, O. Preparation of Aluminium borohydride and its application in organic reductions. Nature 176, 1081-1081 (1955).

47. Jeon, E. \& Cho, Y. Mechanochemical synthesis and thermal decomposition of zinc borohydride. J. Alloy Comp. 422, 273-275 (2006).

48. Pal, B. \& Giri, P. K. Room Temperature Ferromagnetism in Co-Doped ZnO Nanoparticles: Milling Time Dependence and Annealing Effect. Int. J. Nanosci. 10, 1-5 (2011).

49. Song, J.-L., Zheng, J.-H., Zhao, Z., Zhou, B.-Y. \& Lian, J.-S. Synthesis and photoluminescence of $\mathrm{Y}$ and $\mathrm{Cd}$ co-doped $\mathrm{ZnO}$ nanopowder. Trans. Nonferrous Met. Soc. China 23, 2336-2340 (2013).

\section{Acknowledgments}

This work was supported by NSFC (Grant No. 51371018, 50971010, 51371015 and 11174023), the Fundamental Research Funds for the Central Universities

(FRF-BR-14-001B), SRF and SEM from Chinese Education Ministry.

\section{Author contributions}

Yujun S. conceived the idea and designed the project, discussed with W.Y. and R.W. Yujun S., X.S., J.W., S.L., Yuan.S., X.Z. and R.W. carried out the nanoparticles synthesis, XRD measurements, TEM, HR-TEM, UV-vis, PL and EDX characterization. W.Y., Yujun S., X.S and J.W. did the XPS and magnetic measurement. R.W., Yuan.S. and Yujun S. conducted the STEM-HAADF characterization. Yujun S., R.W., W.Y., Yuan.S. and J.W. did the data analysis. Yujun S., W.Y. and R.W. wrote the paper.

\section{Additional information}

Supplementary information accompanies this paper at http://www.nature.com/ scientificreports

Competing financial interests: The authors declare no competing financial interests.

How to cite this article: Wang, R. et al. A General Strategy for Nanohybrids Synthesis via Coupled Competitive Reactions Controlled in a Hybrid Process. Sci. Rep. 5, 9189; DOI:10.1038/srep09189 (2015)

This work is licensed under a Creative Commons Attribution 4.0 International License. The images or other third party material in this article are included in the article's Creative Commons license, unless indicated otherwise in the credit line; if the material is not included under the Creative Commons license, users will need to obtain permission from the license holder in order to reproduce the material. To view a copy of this license, visit http://creativecommons.org/licenses/by/4.0/ 